Document downloaded from:

http://hdl.handle.net/10251/89678

This paper must be cited as:

Molina Moreno, F.; Martí Albiñana, JV.; Yepes Piqueras, V. (2017). Carbon embodied optimization for buttressed earth-retaining walls: Implications for low-carbon conceptual designs. JOURNAL OF CLEANER PRODUCTION. 164:872-884.

doi:10.1016/j.jclepro.2017.06.246

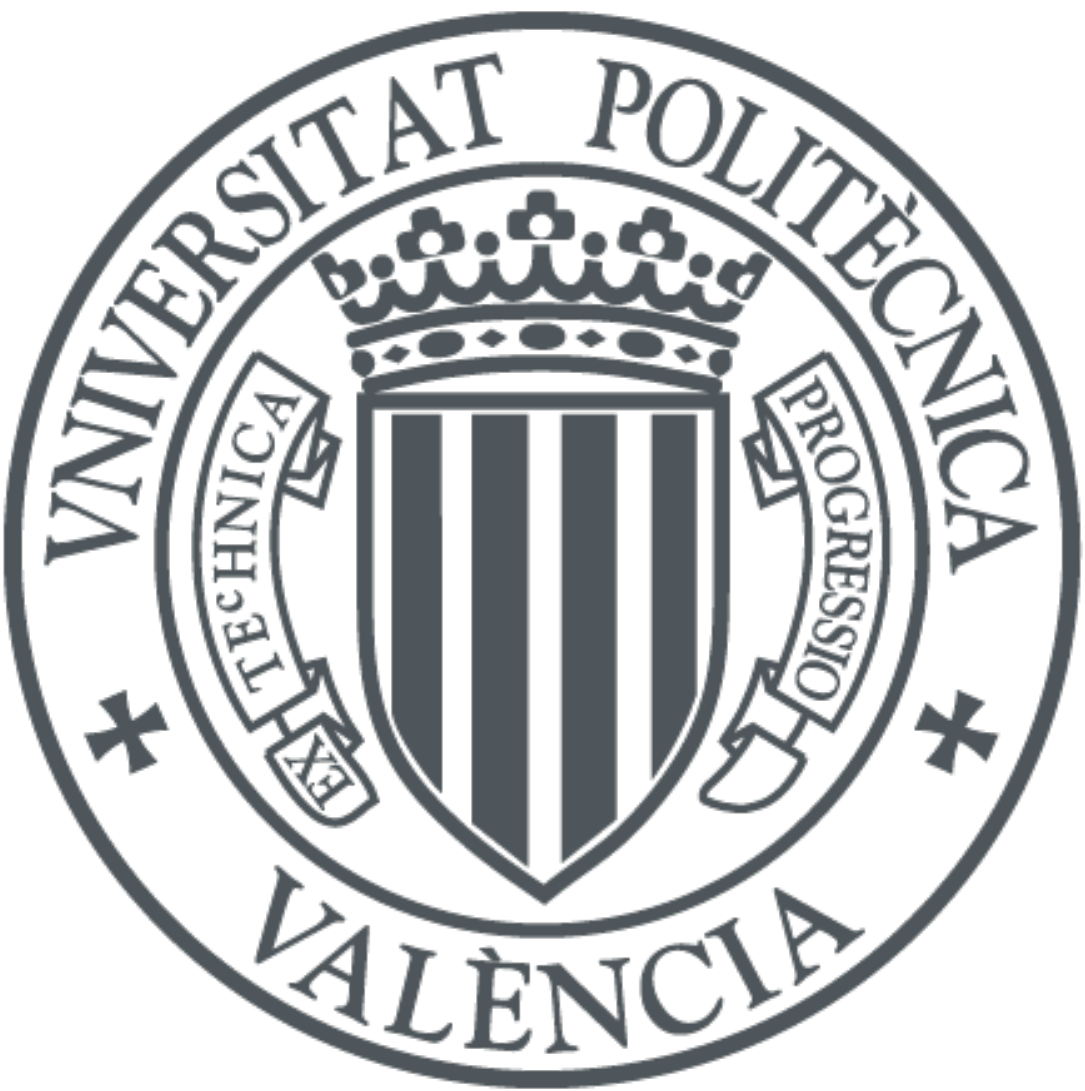

The final publication is available at

http://dx.doi.org/10.1016/j.jclepro.2017.06.246

Copyright

Additional Information 


\title{
Carbon embodied optimization for buttressed earth-retaining walls: implications for low-carbon conceptual designs
}

\author{
Francisca Molina-Moreno ${ }^{1}$, José V. Martí2 ${ }^{2}$ Víctor Yepes ${ }^{2, *}$ \\ ${ }^{1}$ Dept. of Transport Infrastructure and Engineering, Universitat Politècnica de València, 46022 \\ Valencia, Spain \\ ${ }^{2}$ Institute of Concrete Science and Technology (ICITECH), Universitat Politècnica de València, \\ 46022 Valencia
}

\section{7 words}

\begin{abstract}
This paper shows the differences between the design of a reinforced concrete structure considering two objectives to minimize; economic cost and $\mathrm{CO}_{2}$ emissions. Both objectives depend on the amount of two high carbon intensive materials: cement in the concrete and steel; therefore, these objectives are related. As the balance between steel and cement per $\mathrm{m}^{3}$ of concrete depends on several factors such as the type of structure, this study focuses on buttressed earth-retaining walls. Another factor that determines the balance between steel and concrete is the height of the wall. Thus, the methodology considers a parametric study for optimal designs of buttressed earth-retaining walls, where one of the parameters is the wall height. One of the objectives is to show the variation in cost when $\mathrm{CO}_{2}$ is minimized, respectful of minimizing the economic cost. The findings show that wall elements under bendingcompressive strains (i.e. the stem of the buttressed retaining wall) perform differently depending on the target function. On one hand, the study reveals an upward trend of steel per unit volume of concrete in emission-optimized earth-retaining buttressed walls, compared to the cost-optimized. On the other hand, it is checked that unlike the cost-optimized walls, emission-optimized walls opt for a higher concrete class than the minimum class available. These findings indicate that emission-optimized walls penalize not only concrete volume, but also the cement content, to the extent that a higher concrete class outperforms in reduced emissions. Additionally, the paper outlines how and to what extent the design of this typology varies for the two analysed objectives in terms of geometry and amount of materials. Some relevant differences influencing the geometry of design strategies are found.
\end{abstract}

\section{Keywords}

Carbon emission, $\mathrm{CO}_{2}$, earth-retaining wall, reinforced concrete, harmony search, threshold accepting.

\footnotetext{
* Corresponding author. Phone -34963879563; Fax: +34963877569.

E-mail addresses: framomo4@upvnet.upv.es (F. Molina-Moreno), jvmartia@cst.upv.es (J.V. Martí), vyepesp@cst.upv.es (V. Yepes).
} 
Carbon emissions represent one of the largest contributions to global warming so the reduction of carbon-intensive products in structural engineering is of wider concern. Emissions are to be determined for every structure, so $\mathrm{CO}_{2}$ is currently investigated as an optimization target. Yepes et al. (2012), analysed the implications of both optimization objectives in cantilever earthretaining walls. Subsequent studies considered multiobjective optimization of cost and carbonemissions. Yepes et al. (2015), considered cost and emissions in the comparative optimization of cast-prestressed concrete U-beam road bridges, concluding that the two objectives lead to slightly different solutions. Subsequent studies (García-Segura et al., 2016; Martí et al., 2016) considered the optimization towards the two objective functions in post-tensioned concrete box-girder road bridges.

Unlike the aforementioned studies, this research considers only passive instead of prestressed reinforcement. The efficiency of pursuing a low-carbon strategy against a reduced cost one is tested through this study. One of the objectives is to differentiate between $\mathrm{CO}_{2}$ emissions and cost functions according to the mechanical behavior of structures. Traditionally, the economical factor has conventionally been the mainstream objective to minimize, so the ratio of reinforcement $\left(\mathrm{kg} / \mathrm{m}^{3}\right)$ is a classic feature used to benchmark minimum cost and carbon alternatives. One of the objectives of the present study is to quantify how much the optimization target influences on the different reinforcement rates of the wall. However, the ratio of reinforcement does not seem to be the unique indicator of environmental efficiency, given that the environmental performance of concrete is also sensitive to the best cement manufacturing technology available (Kajaste and Hurme, 2016) and the recycled steel rate, as shown in previous work for the type of structure analysed in this paper (Zastrow et al., 2017).

Another point of interest lies in the fact that embodied emissions of concrete are conditioned to the content of clinker in the concrete dosages. Conversely, mixes are not uniform along the concrete classes, and so do the necessary volumes in reinforced structural wall elements. Furthermore, as the mechanical behavior of reinforced concrete bending-compressive structural elements is dependent on both concrete and steel reinforcement together, little relationship is possible among design variables and the concrete class $f_{c k}$, exclusively. These reasons, together with the non-linear structural behavior do not allow for a possible straightforward relationship between emissions and the use of a specified compressive strength in a concrete structure. It is studied whether there is some range for minimizing emissions by using higher concrete classes. A research need was identified when it comes to evaluate the convenience of using a greater compressive strength, whenever it procures fewer emissions. In this sense, the studies of Habert and Roussel (2009), proved that greater strength allows for a reduction in concrete volume in structures that carry only their own weight. Habert et al. (2012), studied whether an improvement in concrete strength would produce a significant difference on the bridge of study. It pointed out the life cycle impact results of a traditional and high performance concrete in two bridge solutions. García-Segura et al. (2014), compared four different compressive strength classes in their studies of precast prestressed bridges. Next, García-Segura et al. (2015), also analysed the influence of the objective function in the amount of concrete and steel in the beams and slab of the bridge. Their conclusions about the influence of the emission objective on the volume of concrete led us to undertake the comparison of objective functions in other structural typologies. 
The methodology for the optimization is the use of a heuristic procedure, Harmony Search (HS). HS was also built upon life cycle cost and embodied emissions of buildings (Fesanghary et al., 2012) and columns (Kripka and de Medeiros, 2012) in the definition of conceptual design guidelines. In alignment with our work, the $\mathrm{CO}_{2}$ optimization in reinforced concrete structures, like building frames, was previously analyzed by Paya-Zaforteza et al. (2009) with Simulated Annealing algorithm and later Camp and Assadollahi (2013) performed a multiobjective optimization considering not only $\mathrm{CO}_{2}$ but also economic costs. The comparison of $\mathrm{CO}_{2}$ and cost optimizations has not been performed yet in with the purpose of obtaining design implications of either target functions. Therefore, our work undertakes this task.

Previous studies analyzed the influence of the type of fill and maximum bearing capacity on the variables of cost optimized solutions of earth retaining cantilever (Yepes et al., 2008) and buttressed walls (Molina-Moreno et al., 2017). The carbon embodied target is narrowly linked to economical designs in cantilever walls (Yepes et al., 2012) and is presumed a potentially suitable target in other types of wall.

The constraint-based design definition is described in Section 2 and the optimization algorithm is described in Section 3. The analyses of cost and emission-optimized results are shown in Section 4, for each design variable. Since variations in steel content and concrete might hinder economic and environmental differences, Section 4 includes a comparative analysis of results of a carbon-embodied optimization by fixing $f_{c k}$ as one of the influential parameters on global warming potential. Finally, Section 5 summarizes the main outcomes.

\section{Design problem definition}

Two objective functions $f(\boldsymbol{x})$ are considered: embodied emissions and construction cost of the wall. The functions consider the unit $\mathrm{CO}_{2}$ equivalent emissions $e_{i}$ and prices $p_{i}$ and the measurements of the corresponding units for each part of the wall. These construction units correspond to materials, formwork and works of excavation and earth-fill. The emission and cost functions are based on a 1 meter wide strip. Unit prices and emissions are given in Table 1 and correspond to the values considered in a previous study on earth-retaining walls (Yepes et al., 2008). The ultimate (ULS) and service (SLS) state limits determine the constraints to satisfy, according to Eq. (1).

Minimize $f(x)$

$$
\text { Subject to } x_{i} \in X_{i}, \quad i=1,2, \ldots, N
$$

where $f(x)$ is an objective function where $\mathrm{x}$ is the set of each decision variable $\mathrm{x}_{\mathrm{i}} ; \mathrm{x}_{\mathrm{i}}$ is the set of range of possible values for each variable and $N$ the number of variables. No penalty functions are used, as the problem is restricted to feasible solutions. Therefore, the foremost computational effort lies in the evaluation of the ULS and SLS. Both constraints become possibly critical in selecting the dimensions of the foundations, since the design process does not follow the traditional approach of structural predimensioning and dimensioning.

\subsection{Design variables and parameters}

The design variables and parameters define the constructive solution. The geometric variables of the buttressed earth-retaining wall under study are depicted in Fig. 1 and Fig. 2. The retaining wall is defined by 20 design variables summarized in Table 2 . Design parameters are described in Table 3. A standard type of fill $\left(F_{2}\right)$ is considered, corresponding to granular soils with more than $12 \%$ of fines (GW, GS, SM, SL) and fine soils with more than $25 \%$ of coarse grained soil (size 
of $45 \mathrm{~mm}$ or less) Yepes et al. (2012). Soil is determined by its density $\gamma\left(20 \mathrm{kN} / \mathrm{m}^{3}\right)$ and 30 은 internal friction angle. The maximum bearing capacity considered is $0.3 \mathrm{MPa}$. Generally, the relative amount of steel and concrete increases the higher the wall is, the less cohesive the ground is and the lower bearing capacity it presents. The set of combinations of the values of the variables constitutes a space of solutions. These variables correspond to geometry, concrete grades and passive reinforcement of the wall. The variables of dimensions and quantities are discrete, to adapt to real cases. The geometric variables are the thickness of the stem $(\mathrm{em})$, the thickness of the buttresses $(e c)$, the thickness of the footing $(c z)$, the length of the toe $(I p)$, the length of the heel $(I t)$, and the distance between buttresses $(d c)$. The steel type and concrete class are the variables considered for the materials. Steel classes B500S and B400S are considered. Concrete classes between HA-25 to HA-50 are included by discrete intervals of 5 $\mathrm{MPa}$. The remaining variables consider the set-up of reinforcement $\left(A_{1-10}\right)$, shown in Fig. 2 and Fig. 3. The diameter and the number of bars define the reinforcement. Three reinforcement flexural bars defined as $A_{1}, A_{2}$ and $A_{3}$ contribute to the main bending of the stem. The vertical reinforcement of foundation in the rear side of the stem is given by $A_{4}$. The secondary longitudinal reinforcement is given by $A_{5}$ for shrinkage and thermal effects in the stem. The longitudinal reinforcement of the buttress is given by $A_{6}$. The area of the reinforcement bracket from the bottom of the buttress is given by $A_{7}$ and $A_{8}$. The upper and bottom heel reinforcements are defined by $A_{9}$ and $A_{11}$ and the shear reinforcement in the footing by $A_{12}$. The longitudinal effects in the toe are defined by $A_{10}$.

\subsection{Structural evaluation module}

The stem of the wall resists the earth pressure working as a continuous slab supported by columns. The buttresses are generally placed in the rear wall side. This provides the joint system plate-buttress the required bending stiffness, acting as the top of a T-shaped cross-section. The wall acts as a cantilever with a varying section, whose size is maximum in the union of the stem to the foundation (Fig. 1). The union of the stem fitted to the buttresses and to the base-slab turns the wall into a hyperstatic structure due to the coercion of the buttresses in the lower side of the stem. The calculation of the buttress is essentially made as a cantilever with varying depth. The cross-section in the top of the stem is quite small, so the horizontal bending is similar to a continuous slab between supports. The buttress acts as the web of a concrete T-beam cross section, whose size varies with the slope of the buttress (Fig. 2).

The structure is checked according to Spanish specifications (Ministerio de Fomento, 2008) and recommendations (Ministerio de Fomento, 2007). Flexural and shear state limits as well as the cracking state limit are considered. The hyperstatic structure is checked according to the method of Huntington (1957). The limit states of the structure are verified for uniform surface loading on top of the fill (Calavera, 2001). Calculation of the active earth pressure depends on the fill and surface loads. The key forces considered in the wall analysis are the weight of the wall, the fill loading on the heel, the earth pressure, the surface load, the weight on the front toe, and the passive resistance in front of the toe. The load on the buttresses is obtained from the pressure distribution over the stem multiplied by the distance between buttresses.

The stem is subject to both bending and shear efforts diminished by the effect of every buttress that is placed at a distance $d c$ (Fig. 2). Unlike the top of the stem that acts as a cantilever, the bottom of the stem is subject to considerable coercion from the footing and the bottom of the buttress, situated in the rear side of the stem. The bending moments in the half section between the buttresses are given by $M_{1}$ and $M_{2}$ : 


$$
\begin{gathered}
M_{1}=-0.03 p_{1} d c(H-c z) \\
M_{2}=-0.0075 p_{1} d c(H-c z)
\end{gathered}
$$

where $p_{1}$ is the pressure over the slab on the upper side of the footing, $M_{1}$ is the bending moment in the connection of the stem to the footing, and $M_{2}$ the maximum bending moment in the stem (Fig. 4). Provided that the distance between buttresses is lower than half the height, the shear strength $(v)$ in the connection of the plate to the footing is defined as:

$$
v=0.4 p_{1} d c
$$

The moments in every span of the stem due to vertical bending stress in the stem must be accurately estimated according to a trapezoidal pressure distribution (Huntington, 1957) where the maximum value is half the maximum pressure in the upper side of the foundation. The bending moment in the stem can be determined as one of the limiting restrictions that yields slenderness to cross sections (Fig. 4). The vertical bending moment in the upper quarter part of the stem can be negligible by the simplification of Huntington.

Checking of the bending stress in any horizontal T-shape cross-section is obtained by the effective width, as indicated in the Model Code (CEB-FIB, 1990). The equations to evaluate the mechanical capacity to flexure and shear are provided by Calavera (2001) who considers the construction limits of the Spanish EHE Structural Concrete Code (Ministerio de Fomento, 2008). The basic expressions against overturning, sliding and soil stresses, checked considering the effect of the buttresses, are given in Eqs. (5-7). Regarding the overturning condition, Eq. (5) indicates that the favorable overturning moments should be high enough compared to unfavorable overturning moments. $M_{\text {of }}$ is the total favorable overturning moment given by Eq. (6); $M_{\text {ou }}$ is the total unfavorable overturning moment defined by Eq. (7), and $\gamma_{\text {to }}$ is the overturning safety factor that is considered as 1.8 for frequent events.

$$
M_{o f}-\gamma_{t o} M_{o u} \geq 0
$$

$$
R=N^{\prime} \mu+E_{p}
$$

Eq. (8) defines the reaction against sliding, where $N^{\prime}$ is the total sum of weights of the wall and ground located over the toe and the heel; $\mu$ is the base-friction coefficient, and $E_{\mathrm{p}}$ is the passive resistance in front of the toe, obtained by Eq. (9). The sliding moment is produced by the horizontal component of the earth pressure because of the negligible effect of the vertical component.

As general remarks concerning the calculations, the checking module is performed for a 1 meter wide strip, including ultimate flexure and ultimate shear, being the acting shear compared to the ultimate values. Both bending and shear minimum steel bars, and the geometrical minimum, are examined according to Calavera (2001), verifying not to originate a ground reaction force twice as high as the maximum bearing capacity $\sigma_{\mathrm{g}, \text {. }}$. 


\section{Proposed Harmony Search strategy}

The Harmony Search (HS), proposed by Geem et al. (2001), establishes an analogy to the process in which musicians try to polish their melody, so as to attain the best musical harmony. Variations over HS were proposed in lasts years to increase the performance of the basic HS (Alia and Mandava, 2011). HS stands out among a variety of metaheuristics. A number of applications of HS were reviewed by Manjarres et al. (2013). Lee and Geem (2004) proved its robustness compared to gradient-based search. The hybrid HS together with a Threshold Acceptance (TA) strategy is applied here in a comparative study of optimization targets. First, HS confers diversification of the variable space by including randomness, which allows escaping from local optima. TA intensifies the search by converging to a finer solution. TA was combined with other algorithms to study reinforced concrete road box frames with a set of 50 discrete variables (Perea et al., 2008, 2010) and bridge abutments (Luz et al., 2015).

Manjarres et al. (2013) summarized the main characteristics and reviewed the successful applications of HS in engineering structures. However, since there are no stable control parameters that fit various practical optimization applications (Guo et al., 2016), new search strategies are desirable. The HSTA algorithm proposed by García-Segura et al. (2015) combines the effectiveness of HS in the search of a large variable space with the local search through Threshold Accepting (TA) proposed by Dueck and Scheuer (1990). HSTA provides then a diversification and intensification balance to global search and converges to still good solutions. HSTA improved the quality of solution in García-Segura et al. (2015) about 8\% compared to HS. Besides, the greater the number of initial improvised solutions, the greater probability for escaping from local optima, so, an increased number of random feasible solutions is used ( $\mathrm{n}_{\text {нмs }}$ * HMS). The steps of the algorithm structure are following summarized.

- Step 1. Assignment of the algorithm parameters: harmony memory size (HMS), harmony memory considering rate (HMCR), harmony memory probability (HMP), pitch adjusting rate (PAR), maximum number of improvisations without improvement (IWI) and threshold iterations (TI). A design variable pool is built for each design variable.

- Step 2. Harmony memory matrix (HM) is initialized with random values of the design pool. First, the algorithm creates $n_{\text {Hмs }} *$ HMS random feasible solutions. Then, HM is filled with the best HMS solution vectors.

- Step 3. A new harmony vector is improvised. The values of the other decision variables are eligible from a set of possible values in the design variable pools with a probability of equal to (1-HMCR) (Eq. (10)). Otherwise, each value of the new solution has a probability of HMCR to be chosen from the HM. For the final case, the value is selected from a solution vector according to its probability (Eq. (11)). The probability of a solution depends on its position in the ranking ( $j$ ), the first solution being the best one. HMP is a parameter between 0 (matching with a deterministic choice) and 1 (matching simple random sampling). The pitch adjusting determines next whether the value is modified one position up or down with a probability PAR (Eq. (12)).

$$
X_{i}^{\prime} \ll\left\{\begin{array}{c}
X_{i}^{\prime} \in\left\{x_{i}^{1}, x_{i}^{2}, \ldots, x_{i}^{H M S}\right\} \text { with probability HMCR } \\
X_{i}^{\prime} \in X_{i} \text { with probability }(1-H M C R)
\end{array}\right.
$$

$$
p(j)=\frac{\mathrm{HMP}^{j-1} *(1-H M P)}{1-H M P^{H M S}}
$$$$
X_{i}^{\prime} \in x_{i}^{j} \pm 1 \text { with probability } P A R
$$ 
- Step 4. Harmony memory matrix is updated. The new solution replaces the worst harmony if its function value improves upon the worst one. Steps 3 and 4 are repeated until the iterations without improving the best harmony reach a previously calibrated maximum number of iterations (IWI), and mimics, finding a nice harmony.

- Step 5. The intensification stage consists of the local search around the best solution through Threshold Accepting (TA). In each iteration a percentage of the variables is modified $\left(P_{\text {var }}\right)$. TA accepts worse solutions when the increment of the target is lower than a threshold value $(\Delta \mathrm{T})$. Initially, a $1 \%$ increment in the function value is accepted. This threshold value is reduced gradually to zero during half of the $\mathrm{Tl}$, as seen in the convergence of Fig. 5 . Next, only better solutions are accepted. TA performs a number of Tl. Generations of new vectors are iteratively performed, until the termination criteria are satisfied.

The validation modules of the structure and the optimization algorithm are programmed in MATLAB $^{\circledR}$ and run with an Intel ${ }^{\circledR}$ Core $^{\mathrm{TM}}$ i5 $\mathrm{CPU}$ with $2.80 \mathrm{GHZ}$. The HS parameters setting is performed by an experiment process considering the parameters of Table 4. The parameters tested are based on the best performing results in $10 \mathrm{~m}$-high walls from previous work (MolinaMoreno et al., 2017). In the attempt to minimize the objective function but also to reach reasonable processing times, the calibration was performed with the highest wall in order to build upon the most demanding computational effort. The parameters were obtained as a result of nine test runs, from which the five most satisfactory targets and processing times are shown in Table 5. Every case was performed nine times to obtain the mean, standard deviation and minimum values of the results. This ensures the quality of the results for each objective according to the methodology proposed by Payá-Zaforteza et al. (2010), based on the extreme value theory.

\section{Results of the Design Parametric Analysis}

The results of the parametric study reveal that the emissions of optimized earth-retaining walls exhibit an overall good performance. The parametric study was performed on a set of different wall heights from 4-16 m with increments of $1 \mathrm{~m}$. This section describes the performance of the two objective functions: emissions $E$ and costs $C$. The results of the cost and emission optimizations are compared between each other. We also analyzed the influence of the reinforced concrete design variables on the geometrical variables and on steel and concrete amounts. As regards the design constraints, the findings confirm that the flexural constraint of the buttress is relevant for minimum carbon walls, as well as the shear constraint both in the buttress and the base slab. The influence of concrete characteristic strength and the wall height are also described. Note that all the values depicted are based on the average values of nine runs.

Fig. 6 shows the parabolic trends for the emissions obtained with a carbon embodied optimization with an economic optimization. It also illustrates the equivalent costs of the emission optimization and the equivalent emissions to a cost optimization. It can be seen that the emissions' optimized solutions are just as expected, i.e. lower values of emissions than the cost-optimized ones. The values of embodied carbon adjust to a curve $E_{c}=57.122 \mathrm{x}^{2}-457.86 \mathrm{x}+$ 1564.8 with a correlation $R^{2}=0.9985$. Similarly, the cost adjusts to the curve $C=51.705 x^{2}$ $294.55 x+869.2$ with $R^{2}=0.9966$. Note that the parabolic tendency indicates that the taller the wall, the lower the efficiency in terms of carbon intensity. 
Fig. 7 shows the relationship between cost and emissions when the objective function is either the cost or the $\mathrm{CO}_{2}$ equivalent emissions on the 1.0 meter wide strip. The trend exhibits a linear progression with respect to cost, equal to $2.9352 x-656.69$, with a correlation $R^{2}=0.9968$. As a rule of thumb, this means 1 Euro reduced in cost would save $2.93 \mathrm{~kg}$ of $\mathrm{CO}_{2}$ equivalent. Similarly, the cost respect to emissions adjusts to $2.6714 \mathrm{x}-625.19$ with $\mathrm{R}^{2}=0.9961$. The unit of $\mathrm{kg} \mathrm{CO}_{2}$ equivalent per linear meter reduced would increase by 0.38 Euros, based on mean values.

Table 6 outlines the amount of $\mathrm{CO}_{2}$ emissions produced by the work units for every wall height. Concrete exhibits a greater contribution as expected, but steel and backfill cannot be underestimated. The emissions from concrete drop from $65 \%$ in $4 \mathrm{~m}$ walls to $55 \%$ in $16 \mathrm{~m}$ walls, whereas the steel contribution increases from $17 \%$ to $36 \%$ for $16 \mathrm{~m}$ heights. Representing on average $59.6 \%$ of the emissions, concrete outweighs the steel emissions by $32.4 \%$. However, concrete rates fall with the height of the wall, so only a particular analysis of each part of the wall would be of relevance as regards the contribution of each material.

Regarding design rules and objective functions, a more precise analysis of the results for either of the emission objective functions is needed. Fig. 8 shows the parabolic curves of emissions of the stem and base slab due to the concrete $E_{c}$ and steel $E_{s}$ necessary in the emission-optimized walls. The foundation presents fewer emissions of steel than of concrete. Unlike in the case of the foundation, it is worth noting that the stem presents an almost parallel trend of concrete and steel emissions, which are closer to one another with the height. This is indicative of the variables defining the stem (thickness and reinforcement), which are key variables for the $\mathrm{CO}_{2}$ equivalent objective. Emissions of concrete in the stem adjust to $E_{c}=5.4662 x^{2}-16.639 x+207.39$ with $R^{2}=0.9815$. Emissions from the steel in the stem are equal to $E_{s}=6.0225 x^{2}-18.523 x+35.91$ with $R^{2}=0.9989$. In agreement with results concerning the mechanical behavior of the stem, the strain effort in the rear side of the stem plays a major role in the target emission's function.

\subsection{Comparison of geometrical variables}

It becomes necessary to determine whether the cost-optimized walls and the $\mathrm{CO}_{2}$-optimized walls exhibit similarities in terms of geometric variables. Some limitations are to be considered in the tendencies analysis described here, such as optimizing through discrete values (Table 2) of the large number of variables (32). As a remainder, the variables to modify during the intensification phase of the algorithm are carried out by random choice of $3 \%$ of the 20 variables. Thus, discrete values for the dimensions of the geometric variables provide the great casuistic of results. As a consequence, some scattering is observed in the values of geometrical variables obtained and analyzed herein. The general tendencies are linearly emphasized hereafter, despite some variables that exhibit better adjustment to parabolic curves.

Fig. 9 shows the variation of the variables of an emissions-optimized in contrast to a costoptimized strategy. Values below 1.00 indicate that the emissions optimization seeks smaller geometrical dimensions than in the cost optimization. Despite the scatter, decreasing trends in some dimensions are worth mentioning. The greatest difference is found in the distance between buttresses $(d c)$. Cost-optimized solutions exhibit larger distances than the emissionsoptimized solutions. While $d c$ values range from $68-92 \%$ of those obtained by the cost optimized method (linearly adjusting to $R_{d c}=-0.0135 \mathrm{x}+0.8791$ ), the ratio of length of the toe $I p$ increases $\left(R_{I p}=-0.0112 x+1.0301\right)$. This means that the emissions-optimized solutions prioritize shorter distances between buttresses, and the cost-optimized solutions prioritize higher lengths of the toe, allowing for larger distances between buttresses. This is coherent with the fact that the cost-optimized stems present greater volume of concrete with the height (Fig. 10). As for the 
remainder of the geometrical ratios, the thickness of the base slab, $c z$, the thickness of the stem em and the distances between buttresses, $d c$, seem to decrease for the emission-optimized method compared to the cost-optimized one. This means that such dimensions are reduced with the height in the emission-optimized method. The expressions for the ratio of $c z$ and em adjust to linear trends, as the aforementioned variables. Each of them adjusts, respectively, to $R_{c z}=-$ $0.0094 \mathrm{x}+1.0054$ and $R_{e m}=-0.0112 \mathrm{x}+1.0301$. The length of the footing $\left(I_{\mathrm{t}}+I_{\mathrm{h}}\right)$ exhibits an increasing ratio of $\mathrm{CO}_{2} /$ cost, thus the emission-optimized method prioritizes longer toes with the height in the foundation. However, the length of the total base slab presents a steady ratio.

Fig. 10 shows the volume of concrete ratio of the emissions and cost optimizations. All values remain below 1.00 indicating that the optimization of $\mathrm{CO}_{2}$ uses less concrete than the costoptimized method. Despite the scatter in the results, the ratio of total concrete, in the stem and the foundation, drops, meaning that less concrete with the height is the choice in the emissionoptimized walls. Our results indicate that emissions-optimized walls use $4.85 \%$ less concrete than the cost-optimized walls. Considering each part of the wall individually, the volume of the stem decreases by $10 \%$ and $11.82 \%$ in the base slab. The ratio of concrete volume $\mathrm{CO}_{2} / \mathrm{cost}$ adjusts to $V_{\text {wall }}=-0.0091 x+1.0398$. The findings for this concrete volume ratio suggest that the target function $\left(\mathrm{CO}_{2}\right.$ emissions) would seek a greater amount of steel. However, the use of a greater compressive strength $f_{c k}$ might hinder the influence of the steel weight. The next section describes the influence of $f_{c k}$ on the weight of steel and the concrete volume.

\subsection{Sensitiveness to the concrete class}

This section analyzes the influence of the concrete strength $f_{\mathrm{ck}}$ on the volume of concrete and weight of steel necessary in the emission-optimized objective. As regards emissions per $\mathrm{m}^{3}$, the concrete class is grouped per concrete strength $f_{c k}$ as HA-25 and HA-30, with 25 and $30 \mathrm{~N} / \mathrm{mm}^{2}$ respectively, according to the Spanish Structural Concrete code (Ministerio de Fomento, 2008). The remaining values of $f_{c k}$ present substantial differences in emissions and unit prices, making it ineligible by the algorithm for earth-retaining walls. All the cost-optimized walls sought the lowest $f_{\mathrm{ck}}, \mathrm{HA}-25$, while the emission-optimized ones used both HA-25 and HA-30.

As regards the influence of the concrete strength in the results, every emission-optimized solution shows at first glance that the concrete class used is both HA-25 and HA-30 in walls from $6 \mathrm{~m}$ height in the emissions' optimization. As the use of HA-30 is not the systematic choice as the height increases, one cannot state that the emission objective function favors HA-30 concrete with the height. A comparison between the solutions obtained by the emissions' optimization, for the HA-25 and HA-30 classes, was performed. The geometrical variables, the volume of concrete and the steel weight in the stem and the base slab were compared. Our findings revealed that the distance between buttresses, length of the footing and thickness of the stem - and therefore the volume of concrete - are sensitive to the concrete strength $f_{\text {ck. }}$ The results presented in Figs. 11-15 will be described next.

Fig. 11 shows a linear tendency of the distances between buttresses; the distance using HA-25 adjusts to $D_{\text {but-25 }}=0.1587 \mathrm{x}+2.2737$ and the use of HA-30 adjusts to $D_{\text {but-30 }}=0.1531 \mathrm{x}+2.098$, with a respective correlation $R^{2}=0.8995$ and $R^{2}=0.8827$. The largest difference is obtained for an $11 \mathrm{~m}$-high wall, which gains $0.50 \mathrm{~m}$ on the adjacent buttress with HA-30. This means that the horizontal bending of the stem is influenced by the concrete resistance, as much as the emissions of the volume required of concrete HA-30 are lower than an equivalent reinforced section with greater steel amount. As a reminder, note that the trends of the geometric variables are expected to exhibit some scatter as 1) mean values are obtained from discrete values of the 
variables, and 2) the algorithm's choice is based on random search of the variables that determine the vectors of optimum solutions.

As seen in Section 4.1 (Fig. 9), the length of the footing, does not exhibit any noticeable difference depending on the target function. However, the toe presents a difference in length. Fig. 12 shows parallel parabolic trends for the length of the toe obtained with HA-30 and HA-25. The length for HA-25 adjusts to $L_{\text {toe- } 25}=0.026 x^{2}-0.0904 x+0.3792$ with $R^{2}=0.9882$, and HA-30 can reach an $11 \%$ shorter length. The largest difference is found for the shortest walls (i.e., a maximum difference of $7 \mathrm{~cm}$ is found in length of walls of $4 \mathrm{~m}$ : $30 \%$ ). Fig. 13 shows a different performance nonetheless in the thickness of the stem for HA-30 and HA-25, which exhibits a noticeable divergence with height. Differences of up to $3 \mathrm{~cm}$ can be obtained with HA-30, meaning a reduction of $20 \%$ of the thickness with HA-25. The curve of HA-30 adjusts to $T_{\text {st }-30}=$ $0.0027 x^{2}-0.0131 x+0.2652$ with a correlation $R^{2}=0.9058$, while that for HA-25 is $T_{\text {st }-30}=0.0013 x^{2}$ $-0.0031 x+0.2498$ with $R^{2}=0.9342$.

Fig. 14 illustrates the volume of concrete on a 1.0 meter wide strip when HA-25 or HA-30 are used. The results show a significant difference in the stem wall with the height; the volume decreases by $5.73 \%$ on average when using HA-30. The curve for the volume for HA-30 adjusts to $V_{30}=0.0206 x^{2}-0.0611 x+1.0486$ with $R^{2}=0.9758$ and for HA-25 to $V_{25}=0.0452 x^{2}-0.486 x+$ 2.8184 with $R^{2}=0.9768$. This makes sense, because the taller the wall, the greater the bending stress, so the concrete yields to the use of a greater $f_{\mathrm{ck}}$. The results indicate that the concrete strength is less influential in the foundation than in the stem (i.e. the HA-25 and HA-30 foundation curves are closer). The slight increase in volume when using HA-25 M could be due to the shear stress in the base slab, which agrees with our results of the condition factor obtained when checking the structure: it barely exceeded the limit value of compliance of 1.0.

Fig. 15 shows the sensitiveness of the steel rebar to $f_{\text {ck. }}$ The results show that the weight in the foundation decreases by $4.79 \%$ on average when using HA-30. This is due to a better performance against shear stress in the heel of the foundation. This is confirmed by the structural checking module; the average shear strength condition factor obtained for the heel barely exceeded the acceptance value. The curve of steel weight in the foundation adequately adjusts to $S_{\mathrm{fd}-30}=6.586 \mathrm{x}^{2}-86.238 \mathrm{x}+301.6$, with a correlation of $\mathrm{R}^{2}=0.9964$, using HA-30. Similarly, the curve for HA-25 adjusts to $\mathrm{S}_{\mathrm{fd}-25}=6.1114 \mathrm{x}^{2}-70.999 \mathrm{x}+209.59$ with $\mathrm{R}^{2}=0.9944$. Conversely, and, as expected, the weight of steel in the stem presents negligible sensitivity to the concrete strength, as the compressive stress in the cross section of the stem similarly affects results for both HA-30 and HA-25 classes. This is coherent, as the horizontal bending stress increases due to the size of the T-shaped cross section that decreases as the height increases (see Section 1.3, Fig. 2), regardless of the compressive stress. Consequently, the condition factors affecting the stem obtained, i.e., the negative reinforcement of the stem in the joint to the buttress and the bending constraint of the buttress, so that the optimal feasible solutions barely exceeded the limit of compliance of the constraints.

Our results suggest that wall elements under bending-compressive strains - the stem of the buttressed retaining wall - performed differently depending on the target function. Mapping the aforementioned results, the stem was thinner when concrete HA-30 was used. Despite the reduction in the concrete volume in the stem when the choice is HA-30, the algorithm does not systematically seek greater concrete strength with height. This is presumably due to a good performance of any concrete strength in reinforced concrete compressed and flexuralcompressed sections; the structure satisfies the bending-compressive stress of the stem; its 
limiting performance against bending may be solved with a greater reinforcement area. As regards the influence of $f_{c k}$ on the foundation, little difference was found in the base slab. Therefore, the concrete compressive strength did not turn out as response variable for the emissions target considering the whole structure (stem and foundation). This all makes sense indeed; the stem seems insensitive to concrete strength due to the good compressive performance of the concrete section under bending-compressive stress.

\subsection{Sensitiveness to height on the reinforced cross-section}

The influence of the height affects the use of steel and concrete in a different manner in the emission and cost optimizations, as previously analyzed. This subsection outlines such a difference by means of different ratios: $\mathrm{CO}_{2} /$ cost; and the ratio of the weight of steel $S_{\text {st }}$ in $\mathrm{kg}$ and weight related to the volume of concrete $R_{\mathrm{rf}}$ in $\mathrm{kg} / \mathrm{m}^{3}$ used in the stem and foundation. These variables refer to a 1.0 meter wide strip along the longitudinal dimension of the wall.

Table 7 shows the weight of steel ratio $S_{\text {st }}$, between the emission- and cost-optimized solutions $\left(\mathrm{CO}_{2} / \mathrm{cost}\right)$. Values over 1.00 indicate that greater steel is the preference with height in the cross section by the emission-optimized strategy. The results indicate that emission-optimized walls require more steel than the cost-optimized ones from $12 \mathrm{~m}$-height walls. Then, lower walls exhibit varying total steel use, mainly because the steel in the stem seems not to be clearly sensitive to the optimization target within these lower heights. In contrast, the base slab exhibits an upward and more pronounced trend of steel use. In agreement with the results, the ratio of reinforcement per unit of volume of concrete is expected to increase with the wall height. Greater steel content seemed to be the most environmentally efficient alternative. In agreement with Fig. 10, the higher the wall, the fewer concrete amount for the emission target.

Fig. 16 shows the trend of the reinforcement ratio for the economic and the emission targets of the wall. Also for the whole wall, the total amount of steel is sensitive to the height. When the concrete strength $f_{\mathrm{ck}}$ is fixed in the emission optimization, the ratio of reinforcement reaches equivalent values with the height. The different ratio at lower heights unveils that there is a limit where the algorithm reaches a minimum emission, regardless of $f_{\text {ck. }}$. As of such limit, the concrete strength does not play a major role in the structural performance as the steel does.

\section{Conclusions}

This paper describes a parametric optimization of an earth retaining wall with buttresses using the HSTA algorithm. The comparative analysis is presented considering two objectives: a strategy of minimal carbon and an economic strategy. Working towards the emission target provides stabilized results without impairing the economic target. The results suggested that there is a relationship between cost and $\mathrm{CO}_{2}$ equivalent emissions. It is observed that optimizing emissions generally implies fewer concrete (3.18\%) in the wall than the cost-optimized method. Analyzing the parts of the wall independently, the stem exhibited by average $8.72 \%$ less concrete volume when optimizing emissions. It can be said that the higher the wall, the more steel is sought by the emission target, and less concrete. Also the use of a greater concrete class is beneficial as less volume of concrete is required.

465 As a result of a second analysis, where the concrete class is restricted in the emission optimization, a higher concrete (class HA-30 instead of class HA-25) implied an average reduction of volume equivalent to $5.73 \%$ in the stem of the wall. On the other hand, emissions 

(11.05 $\mathrm{kg} \mathrm{CO}_{2}$ equivalent $/ \mathrm{m}^{3}$ ) on average, which is considered a meaningful amount.

471 However, the results for the stem show how the bending-compressive strain of the stem wall conditions the optimization. The emission optimized walls used both classes HA-25 and HA-30, but the latter was not systematically chosen with the height. These findings imply that the stem is more sensitive to the steel amount than to the concrete class; the higher the wall, the less influential the amount of cement in the mix is, because the main component needed in the wall is the reinforced steel. Thus, the greater the bending effort in this type of structure, the less relevant the optimization objective becomes. The scientific relevance for structural designers is that there is some range for minimizing emissions by using higher concrete classes, although it mainly benefits lower heights.

\section{Acknowledgments}

482 This research was funded by the European Institute of Innovation and Technology under grant 483 agreement no 20140262 Low Carbon Strategy in the Construction Industry 484 (PGA_APED0094_2014-2.1-278_P066-10) and the Spanish Ministry of Economy and 485 Competitiveness along with FEDER funding (Project BIA2014-56574-R). The authors are grateful 486 for the through revision of the manuscript by Tatiana García-Segura.

\begin{tabular}{l|ll|}
488 & Notation & \\
489 & em & stem thickness \\
490 & $c Z$ & footing thickness \\
491 & $l p$ & toe length \\
492 & $p_{i}$ & unit prices \\
493 & $q$ & uniform surface loading on top of the fill \\
494 & $l t$ & heel length \\
495 & $d c$ & distance between buttresses \\
496 & $v_{c}$ & total volume of concrete \\
497 & $x_{1}, \ldots, x_{n}$ & design variables \\
498 & $A_{1}, \ldots, A_{12}$ reinforcement variables \\
499 & $R_{\mathrm{st}}$ & reinforcement of the stem \\
500 & $R_{\mathrm{ft}}$ & reinforcement of the footing \\
501 & $R_{t}$ & total weight of steel \\
502 & $H$ & total height of the wall \\
503 & $H_{2}$ & foundation depth \\
\cline { 3 - 3 } & &
\end{tabular}




\begin{tabular}{l|ll|}
504 & $M_{o f}$ & moment reaction at the base of the wall \\
505 & $M_{o u}$ & total favorable overturning moment \\
506 & $P(\gamma, \phi, \delta)$ & earth pressure \\
507 & $P_{p}$ & passive earth pressure on the toe \\
508 & $Q$ & surface loading on top of the fill \\
509 & $\alpha$ & angle slope of the buttress \\
510 & $\gamma$ & density of the fill \\
511 & $\gamma_{f s}$ & safety coefficient against sliding \\
512 & $\gamma_{f o}$ & safety coefficient against overturning \\
513 & $\phi$ & internal friction angle \\
514 & $\delta$ & wall-fill friction angle \\
515 & $\sigma$ & maximum bearing pressure \\
516 & $\mu$ & base-friction coefficient \\
\cline { 2 - 3 } & &
\end{tabular}

517

\section{References}

Alia, O.M., Mandava, R., 2011. The variants of the harmony search algorithm: an overview. Artif. Intell. Rev. 36, 49-68. http://dx.doi.org/10.1007/s10462-010-9201-y

Calavera, J., 2001. Muros de contención y muros de sótano [in Spanish]. Intemac, Madrid.

Camp, C. V., Assadollahi, A., 2013. $\mathrm{CO}_{2}$ and cost optimization of reinforced concrete footings using a hybrid big bang-big crunch algorithm. Struct. Multidiscip. Optim. 48, 411-426. http://dx.doi.org/10.1007/s00158-013-0897-6

CEB-FIB, 1990. Model Code. Design code. Thomas Telford Services Ltd., London.

Dueck, G., Scheuer, T., 1990. Threshold Accepting: A general Purpose Optimization Algorithm appearing Superior to Simulated Annealing. J. Comput. Phys. 90, 161-175. http://dx.doi.org/10.1016/0021-9991(90)90201-B

Fesanghary, M., Asadi, S., Geem, Z.W., 2012. Design of low-emission and energy-efficient 245-250. http://dx.doi.org/10.1016/j.buildenv.2011.09.030

García-Segura, T., Yepes, V., Martí, J. V., Alcalá, J., 2014. Optimization of concrete l-beams using a new hybrid glowworm swarm algorithm. Lat. Am. J. Solids. Struct. 11(7), 1190-1205. http://dx.doi.org/10.1590/S1679-78252014000700007

García-Segura, T., Yepes, V., Alcalá, J., Pérez-López, E., 2015. Hybrid harmony search for sustainable design of post-tensioned concrete box-girder pedestrian bridges. Eng. Struct. 92, 112-122. http://dx.doi.org/10.1016/j.engstruct.2015.03.015 
García-Segura, T., Yepes, V., 2016. Multiobjective optimization of post-tensioned concrete boxgirder road bridges considering cost, $\mathrm{CO}_{2}$ emissions, and safety. Eng. Struct. 125, 325-336. http://dx.doi.org/10.1016/j.engstruct.2016.07.012

Geem, Z.W., Kim, J.H., Loganathan, G. V., 2001. A new heuristic optimization algorithm: Harmony search. Simulation 60 76, http://dx.doi.org/10.1177/003754970107600201

Guo, Z., Yang, H., Wang, S., Zhou, C., Liu, X., 2016. Adaptive harmony search with best-based search strategy. Soft Comput. 1-15. http://dx.doi.org/10.1007/s00500-016-2424-3

Habert, G., Arribe, D., Dehove, T., Espinasse, L., Le Roy, R., 2012. Reducing environmental impact by increasing the strength of concrete: quantification of the improvement to concrete bridges. J. Clean. Prod. 35, 250-262. http://dx.doi.org/10.1016/j.jclepro.2012.05.028

Huntington, W.C., 1957. Earth Pressures and Retaining Wall. John Wiley and Sons, New York.

Kajaste, R., Hurme, M., 2016. Cement industry greenhouse gas emissions - management options and abatement cost. J. Clean. Prod. 112, 4041-4052. http://dx.doi.org/10.1016/j.jclepro.2015.07.055

Kripka, M., de Medeiros, G.F., 2012. Cross-Sectional Optimization of Reinforced Concrete Columns Considering both Economical and Environmental Costs. Appl. Mech. Mater. 193-194, 1086-1089. http://dx.doi.org/10.4028/www.scientific.net/AMM.193194.1086

Lee, K.S., Geem, Z.W., 2004. A new structural optimization method based on the harmony search $\begin{array}{llll}\text { algorithm. Comput. } & \text { Struct. } & \text { 781-798. }\end{array}$ http://dx.doi.org/10.1016/j.compstruc.2004.01.002

Luz, A., Yepes, V., González-Vidosa, F., Marti, J.V., 2015. Design of open reinforced concrete abutments road bridges with hybrid stochastic hill climbing algorithms. Inf. Constr. 67(540), e114. http://dx.doi.org/10.3989/ic.14.089

Manjarres, D., Landa-Torres, I., Gil-Lopez, S., Del Ser, J., Bilbao, M.N., Salcedo-Sanz, S., Geem, Z.W., 2013. A survey on applications of the harmony search algorithm. Eng Appl Artif Intell. 26, 1818-1831. http://dx.doi.org/10.1016/j.engappai.2013.05.008.

Martí, J.V., García-Segura, T., Yepes, V., 2016. Structural design of precast-prestressed concrete U-beam road bridges based on embodied energy. J. Clean. Prod. 120, 231-240. http://dx.doi.org/10.1016/j.jclepro.2016.02.024

Ministerio de Fomento, 2007. CTE. DB-SE. Structural safety: Foundations [in Spanish]. Ministerio de Fomento, Madrid

Ministerio de Fomento, 2008. EHE: Code of structural concrete. Ministerio de Fomento, Madrid.

Molina-Moreno, F., García-Segura, T., Yepes, V., Martí, J.V., 2017. Optimization of buttressed earth-retaining walls using hybrid harmony search algorithm. Eng. Struct. 134, 205-216. http://dx.doi.org/10.1016/j.engstruct.2016.12.042

Paya-Zaforteza, I., Yepes, V., Hospitaler, A., González-Vidosa, F., 2009. $\mathrm{CO}_{2}$-optimization of reinforced concrete frames by simulated annealing. Eng. Struct. 31(7), 1501-1508. http://dx.doi.org/10.1016/j.engstruct.2009.02.034 
Payá-Zaforteza I., Yepes V., González-Vidosa F., Hospitaler A., 2010. On the Weibull cost estimation of building frames designed by simulated annealing. Meccanica 45(5), 693704. http://dx.doi.org/10.1007/s11012-010-9285-0

Perea, C., Alcala, J., Yepes, V., Gonzalez-Vidosa, F., Hospitaler, A., 2008. Design of reinforced concrete bridge frames by heuristic optimization. Adv. Eng. Softw. 39(8), 676-688. http://dx.doi.org/10.1016/j.advengsoft.2007.07.007

Perea, C., Yepes, V., Alcala, J., Hospitaler, A., Gonzalez-Vidosa, F., 2010. A parametric study of optimum road frame bridges by threshold acceptance. Indian J. Eng. Mater. Sci. 17(6), 427-437.

Yepes, V., Alcala, J., Perea, C., González-Vidosa, F., 2008. A parametric study of optimum earthretaining walls by simulated annealing. Eng. Struct. 30(3), 821-830. http://dx.doi.org/10.1016/j.engstruct.2007.05.023

Yepes, V., Gonzalez-Vidosa, F., Alcala, J., Villalba, P., 2012. $\mathrm{CO}_{2}$-Optimization Design of Reinforced Concrete Retaining Walls Based on a VNS-Threshold Acceptance Strategy. J. Comput. Civ. Eng. 26(3), 378-386. http://dx.doi.org/10.1061/(ASCE)CP.19435487.0000140

Yepes, V., Martí, J.V., García-Segura, T., 2015. Cost and $\mathrm{CO}_{2}$ emission optimization of precastprestressed concrete U-beam road bridges by a hybrid glowworm swarm algorithm. Autom. Constr. 49, 123-134. http://dx.doi.org/10.1016/j.autcon.2014.10.013

Zastrow, P., Molina-Moreno, F., García-Segura, T., Martí, J.V., Yepes, V., 2017. Life cycle assessment of cost-optimized buttress earth-retaining walls: A parametric study. J. Clean. Prod. 140, 1037-1048. http://dx.doi.org/10.1016/j.jclepro.2016.10.085 


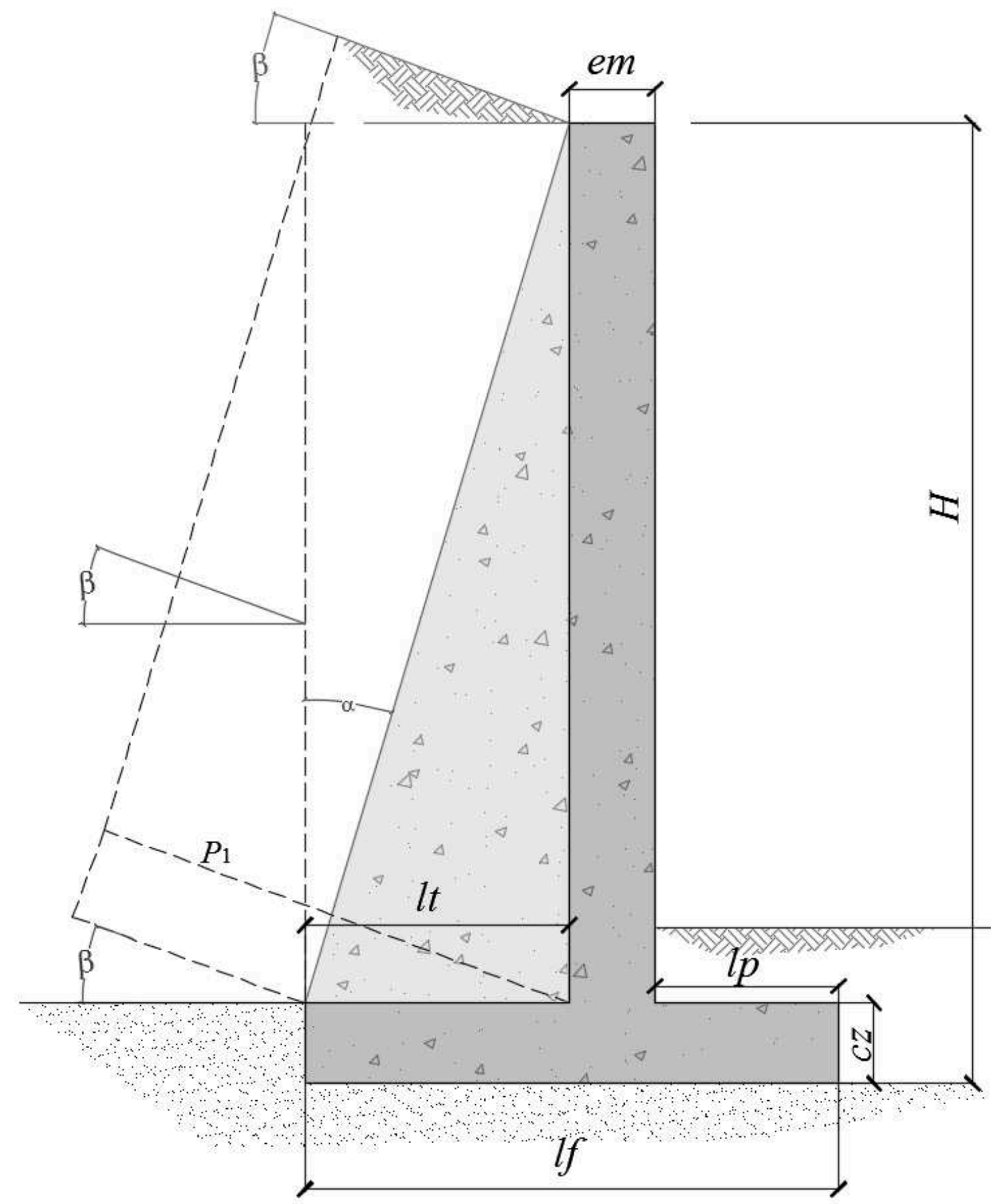

Fig. 1. Geometrical dimensions of a buttressed wall 


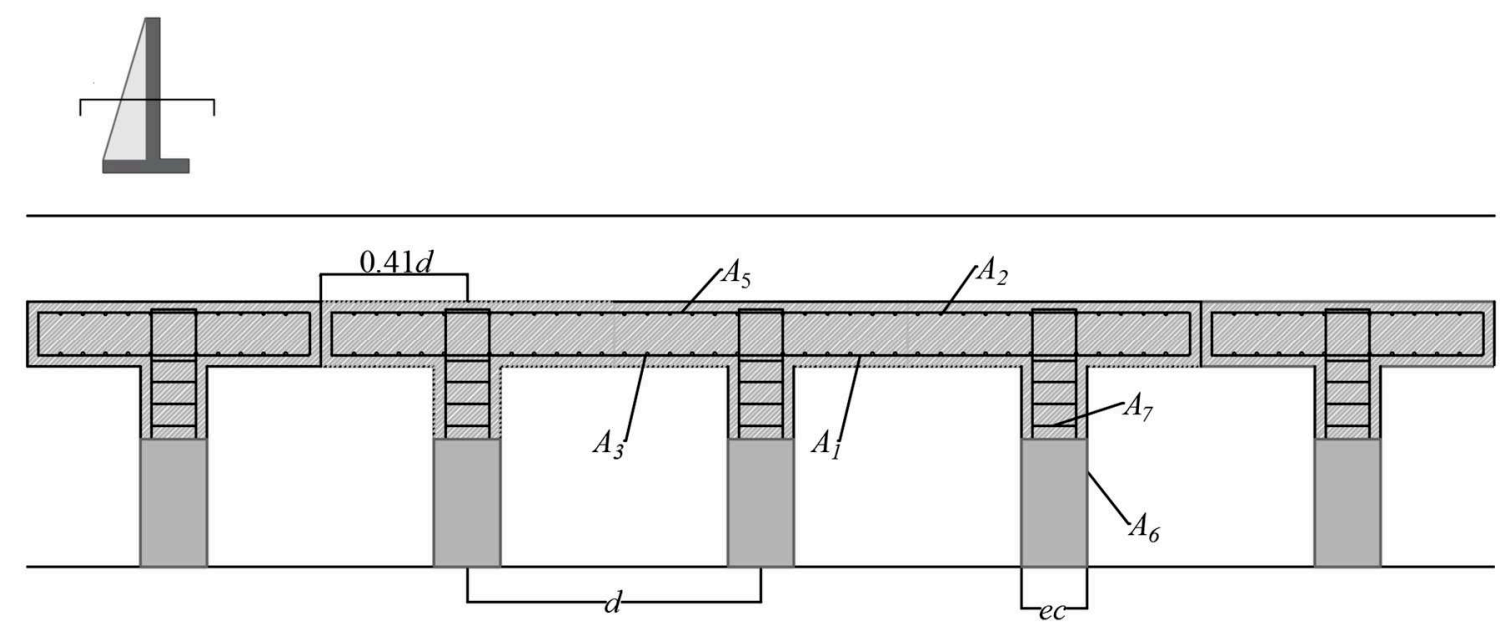

603

604 Fig. 2. Earth-retaining buttressed wall. Floor cross-section 


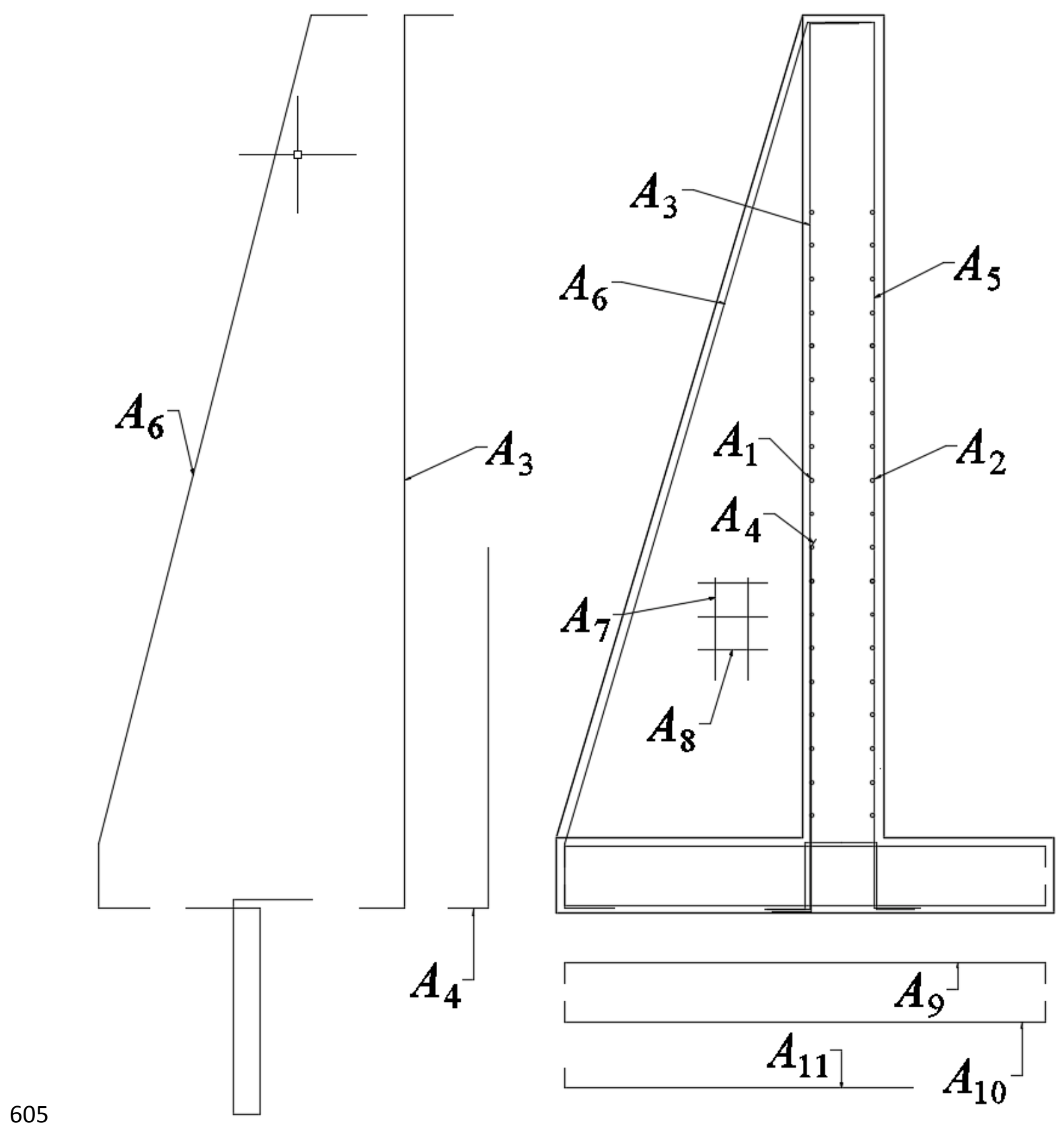

606 Fig. 3. Reinforcement variables for earth-retaining buttressed walls 


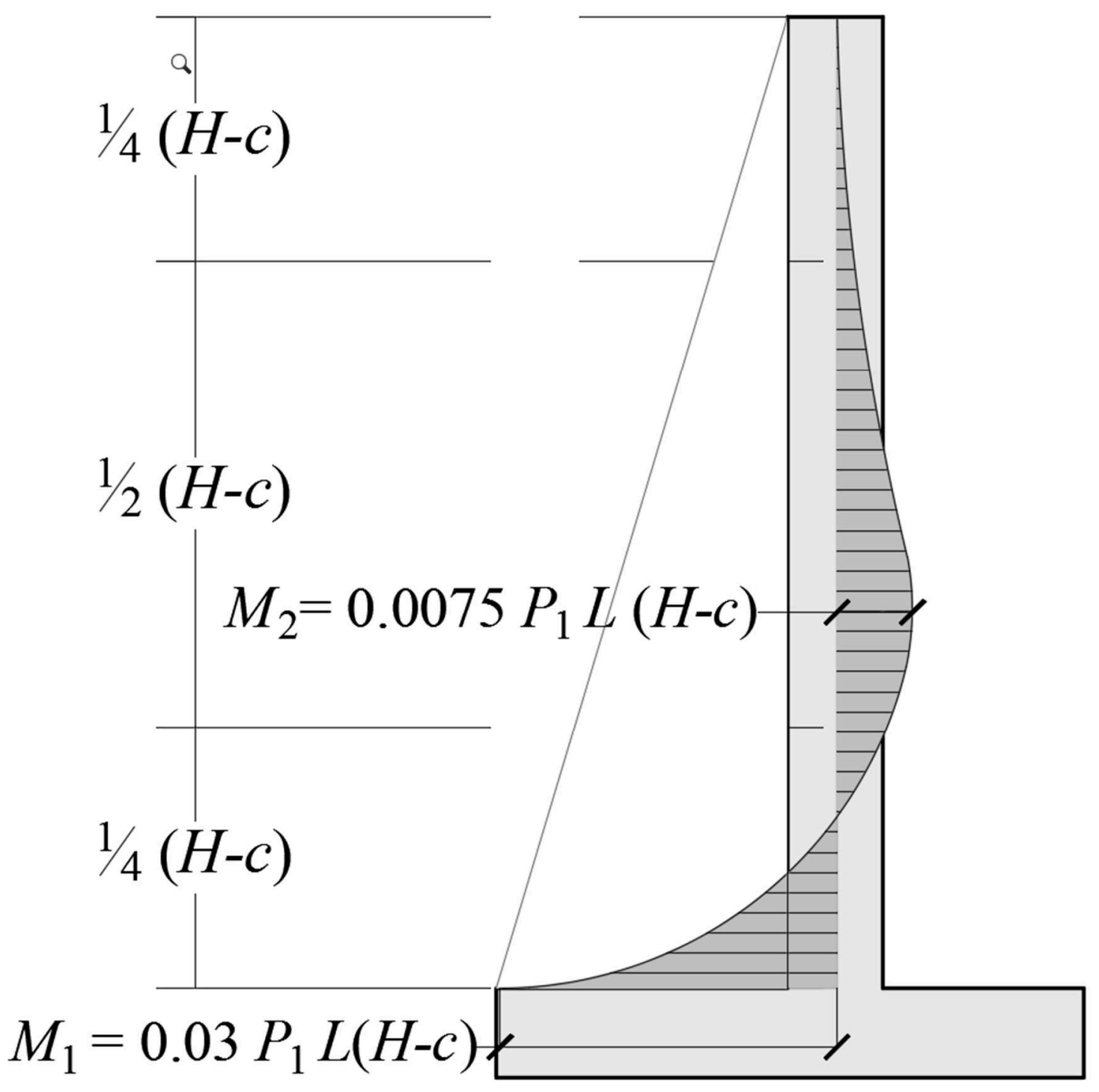

607

Fig. 4. Bending moments of the stem 


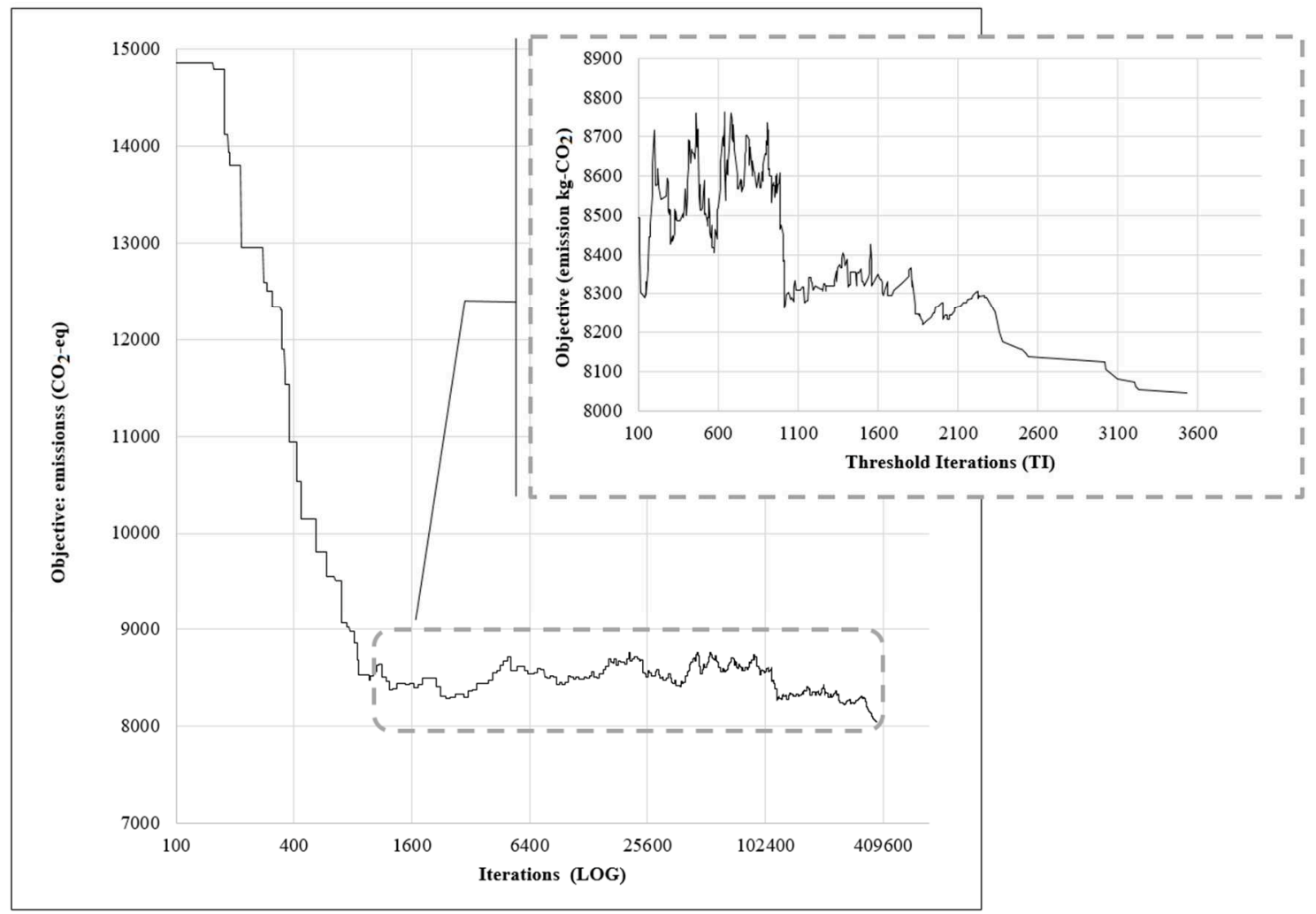

610 Fig. 5. Design history convergence of HSTA for $16 \mathrm{~m}$ height earth-retaining buttressed wall

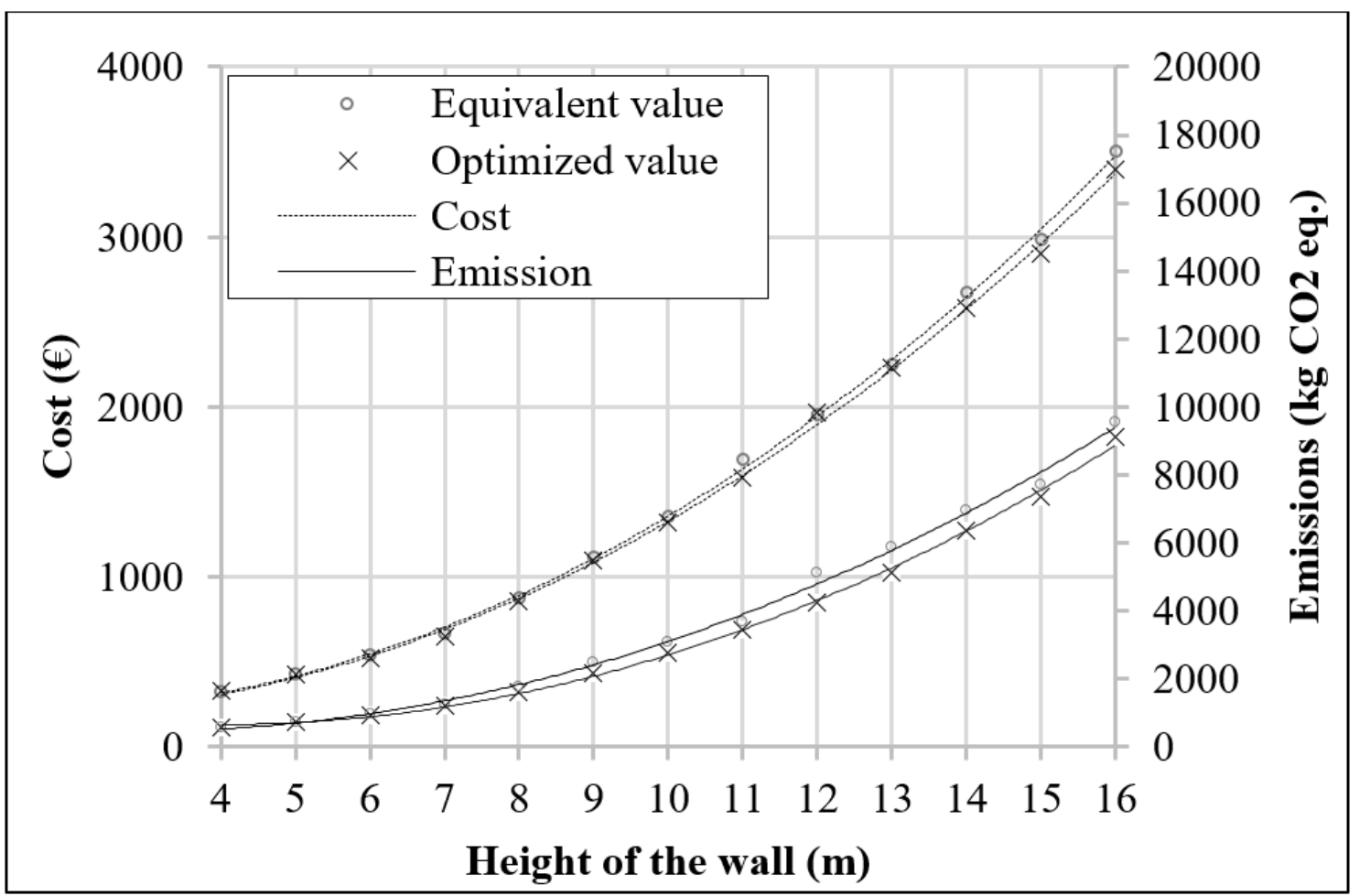

612 Fig. 6. Carbon embodied $\left(\mathrm{CO}_{2}\right.$ equivalent .) and cost $(€)$ optimized solutions with equivalent 613 costs and emissions 


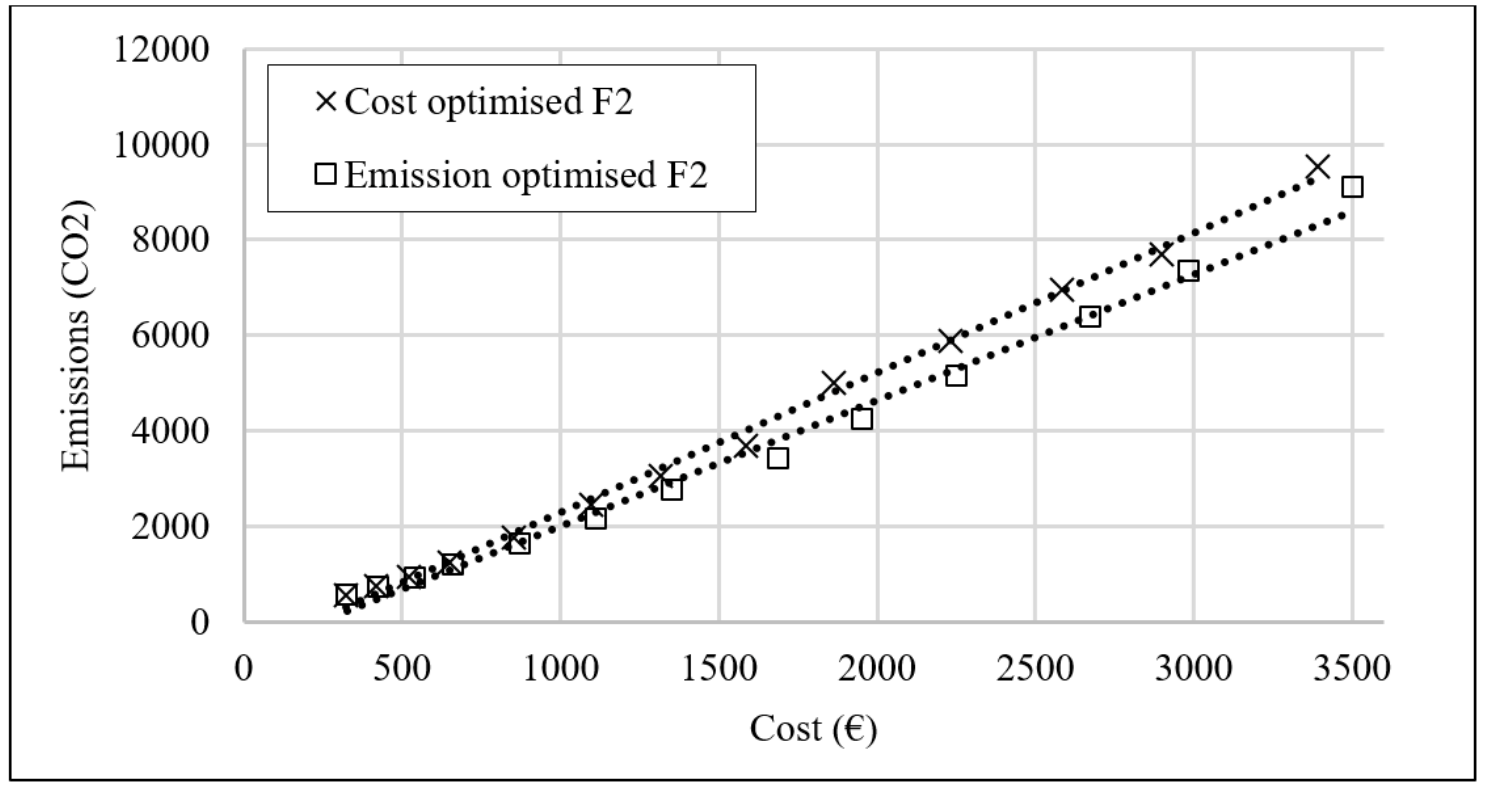

615 Fig. 7. Ratio of emissions-optimized and cost-optimized solutions

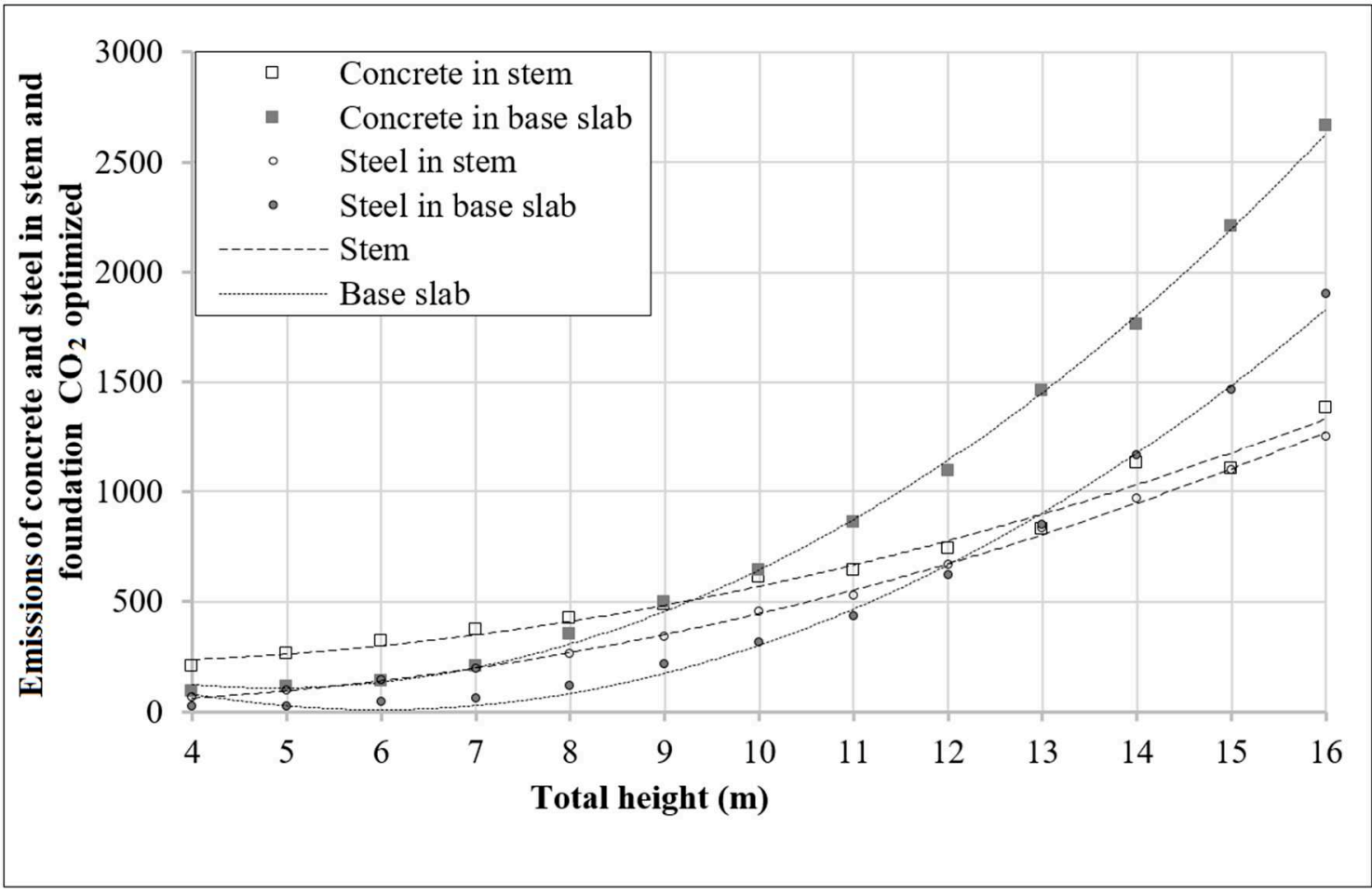

616

617 Fig. 8. Emissions of steel and concrete in stem and foundation for the $\mathrm{CO}_{2}$ optimization strategy 


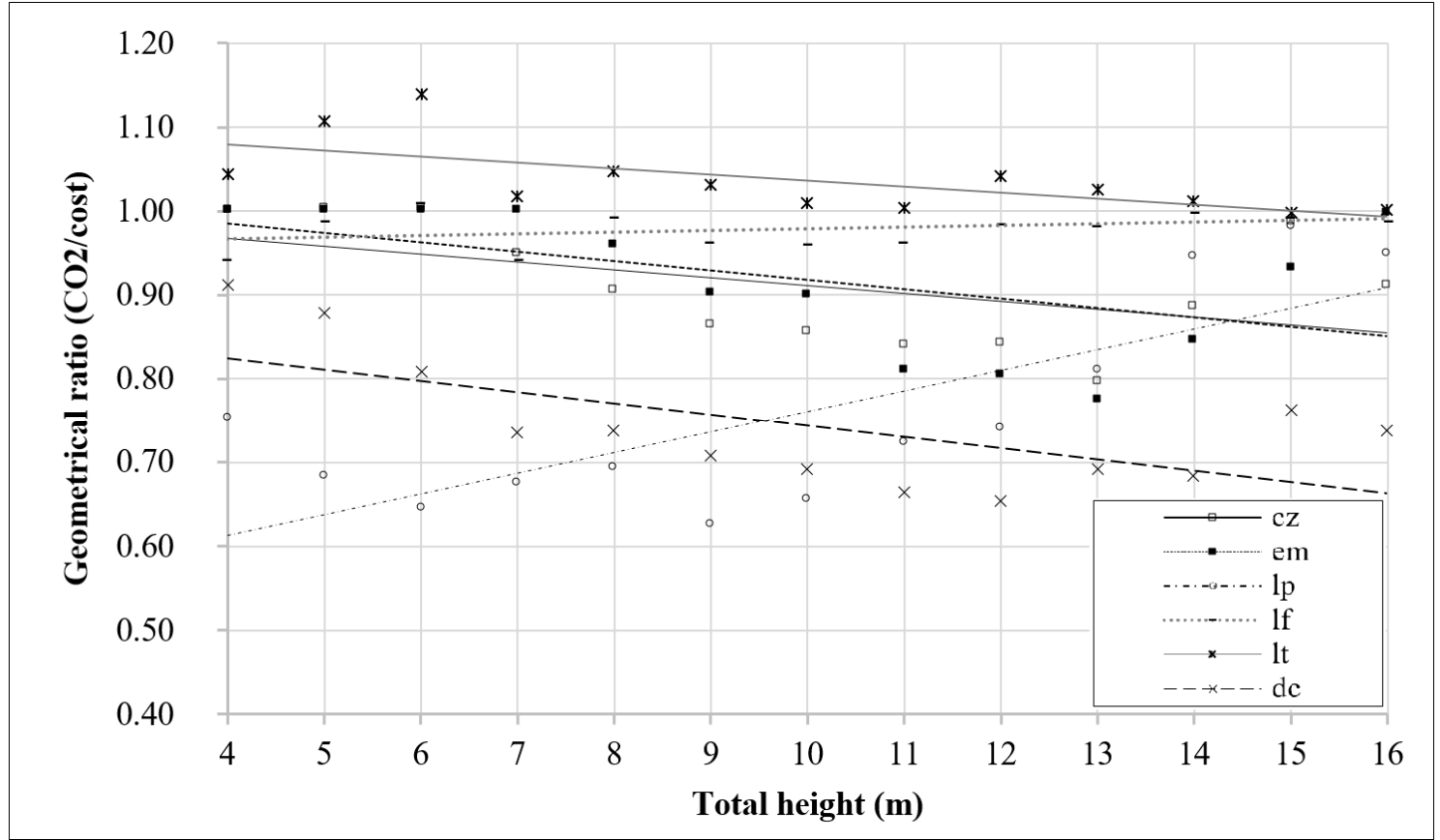

619 Fig. 9. Ratio emission/cost of the geometrical variables

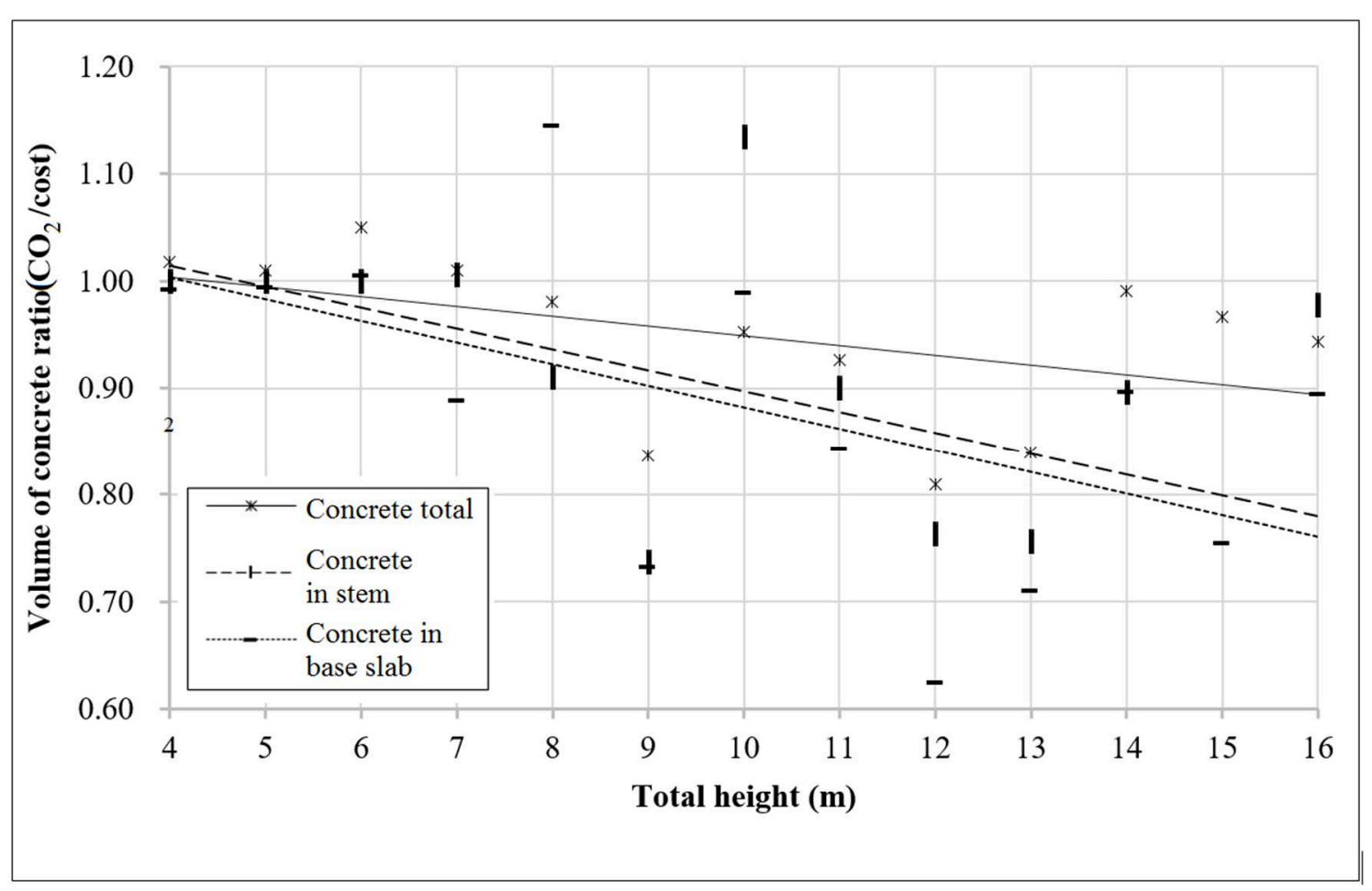

621 Fig. 10. Ratio emission/cost of the volume of concrete 


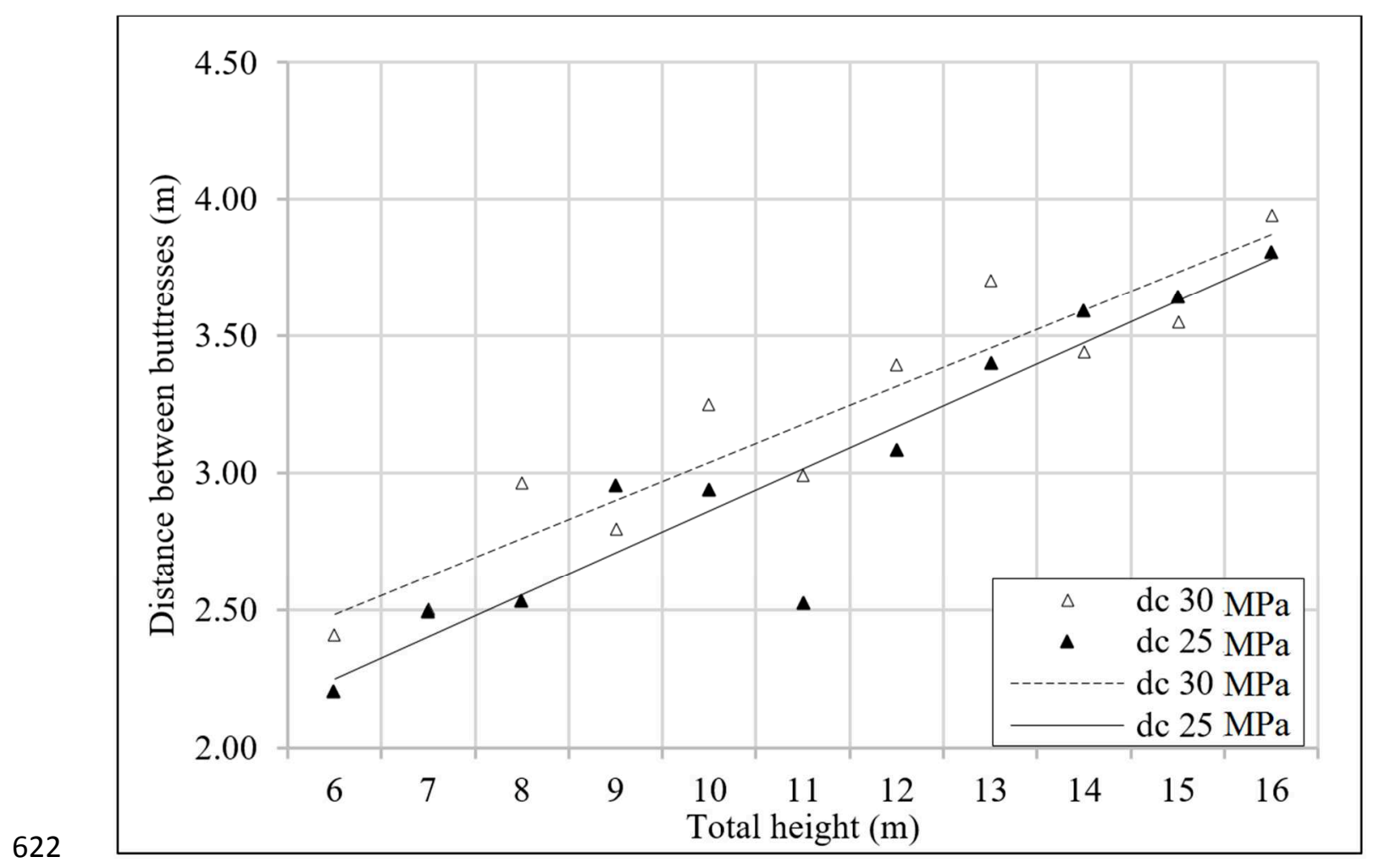

623 Fig. 11. Sensitive variables to concrete strength: distance between buttresses

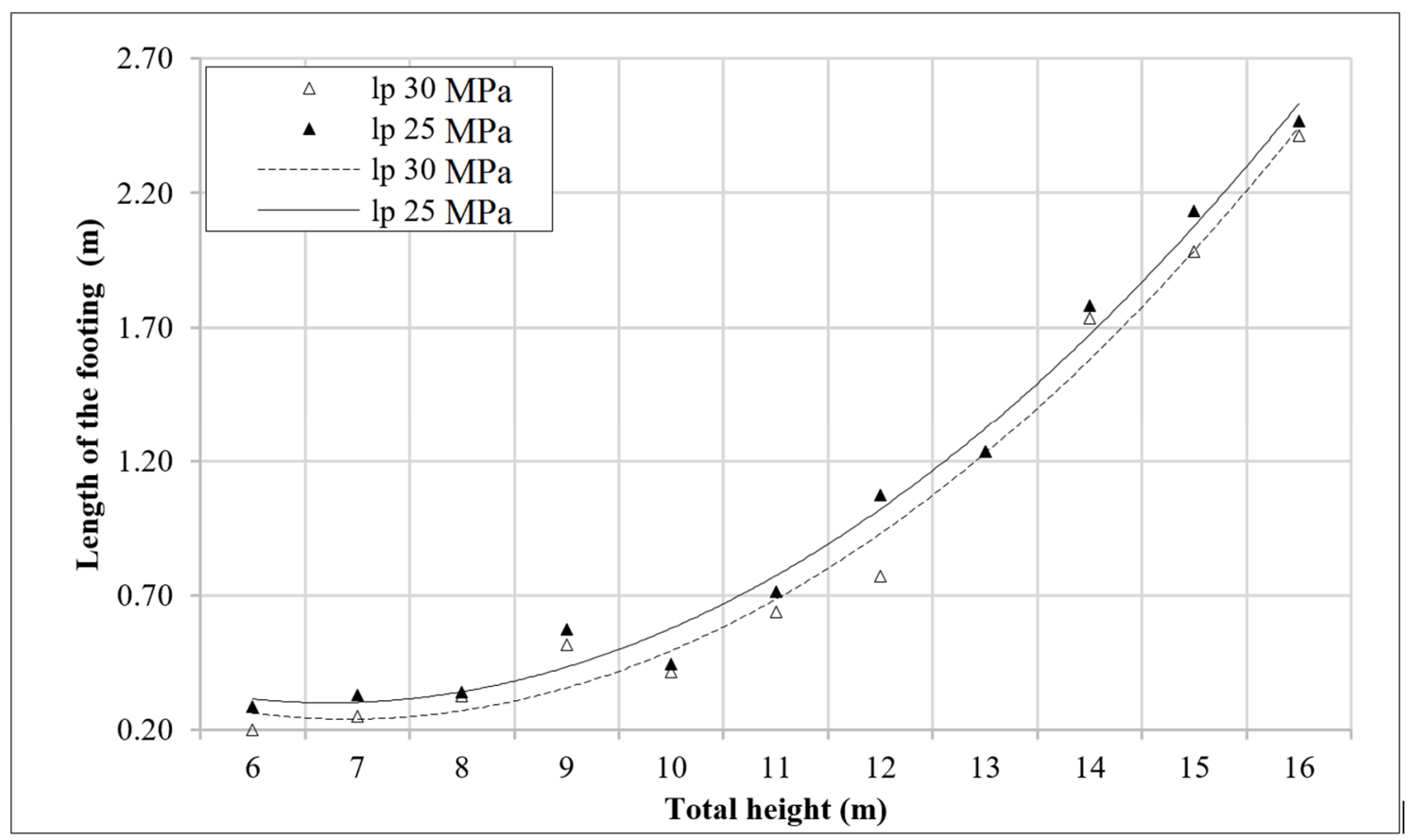

Fig. 12. Sensitive variables to the concrete strength: length of the footing 


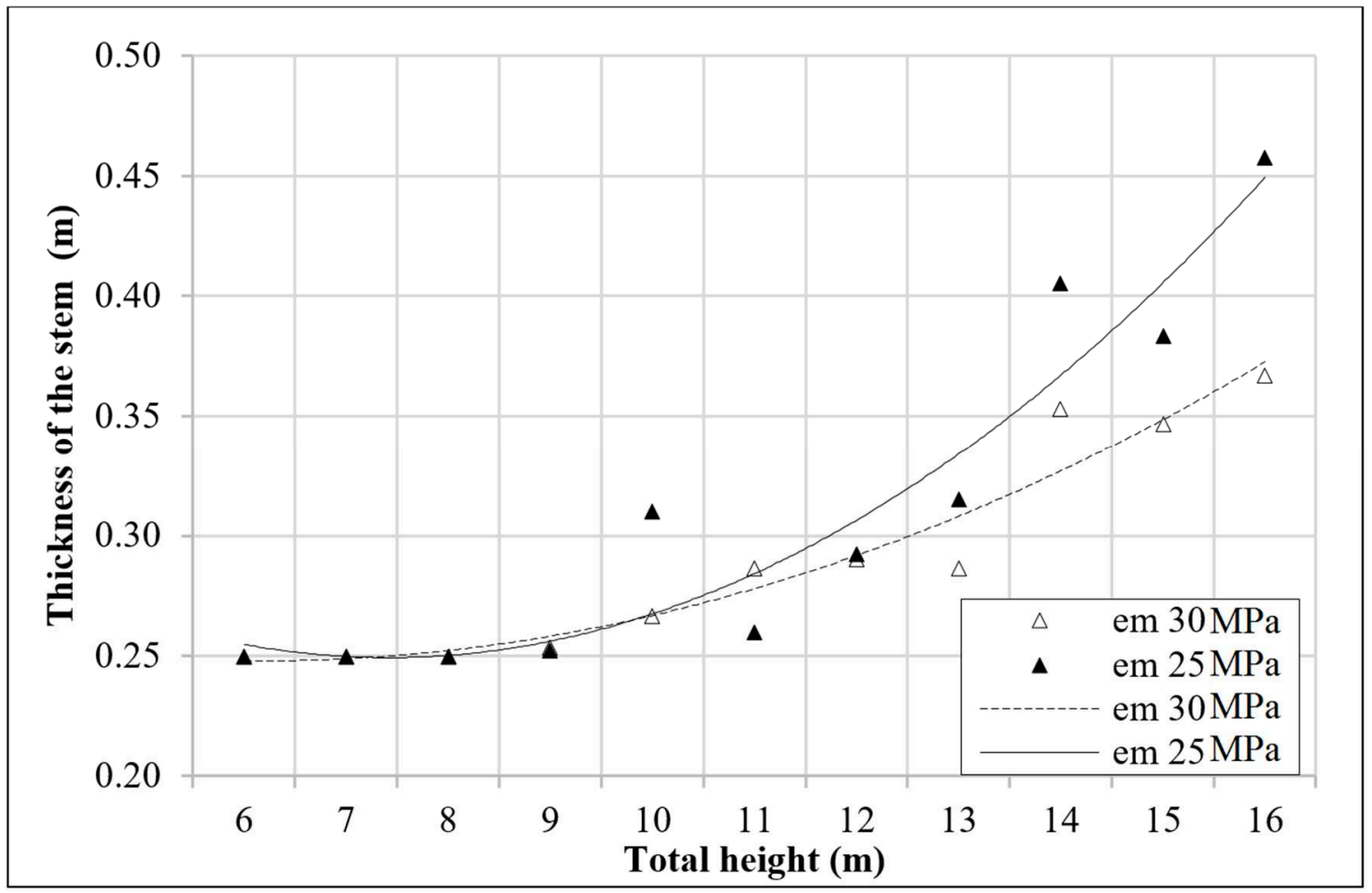

627 Fig. 13. Sensitive variables to the concrete strength: thickness of the stem

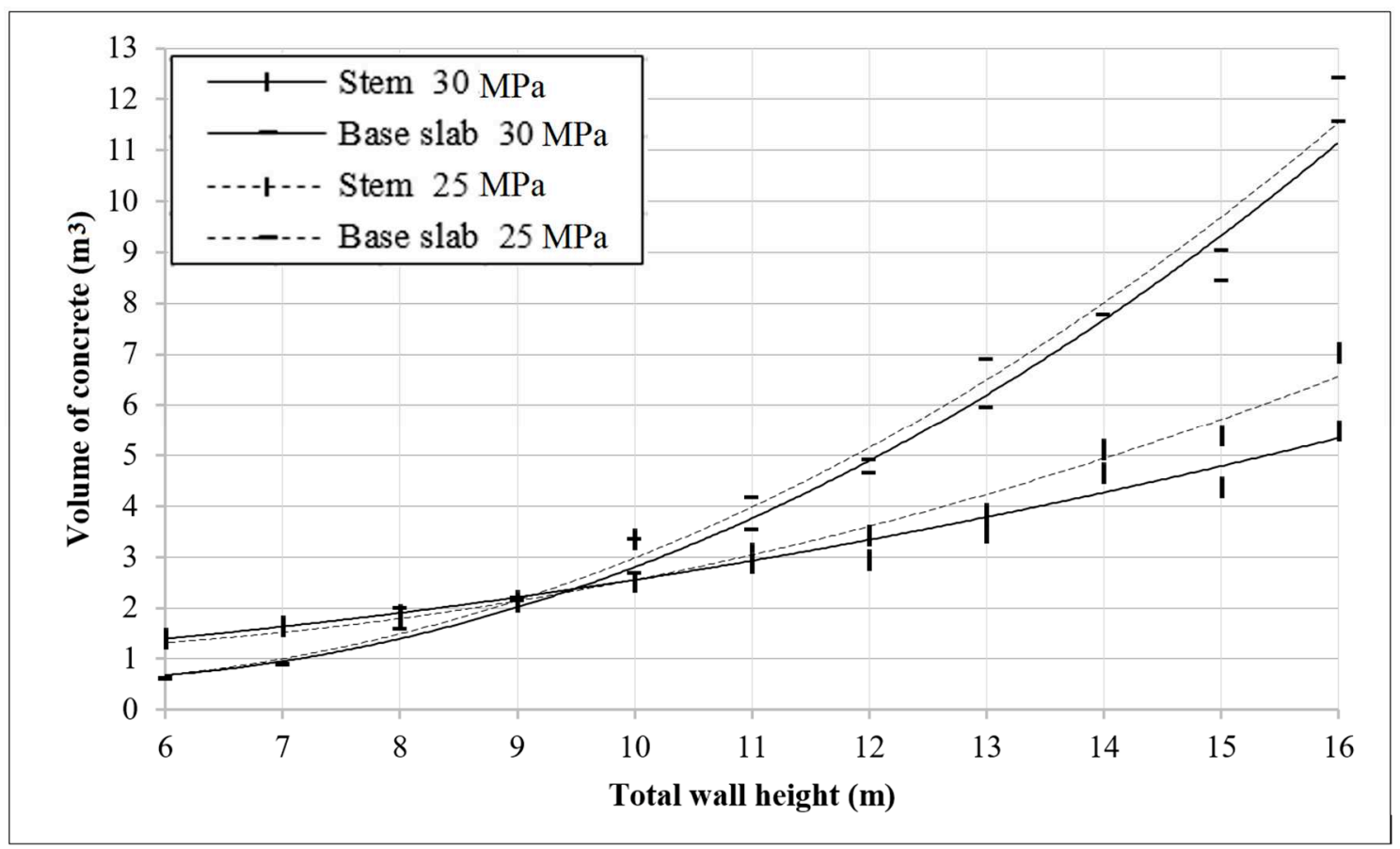

Fig. 14. Sensitivity to the concrete strength: volume of concrete in stem and base slab 


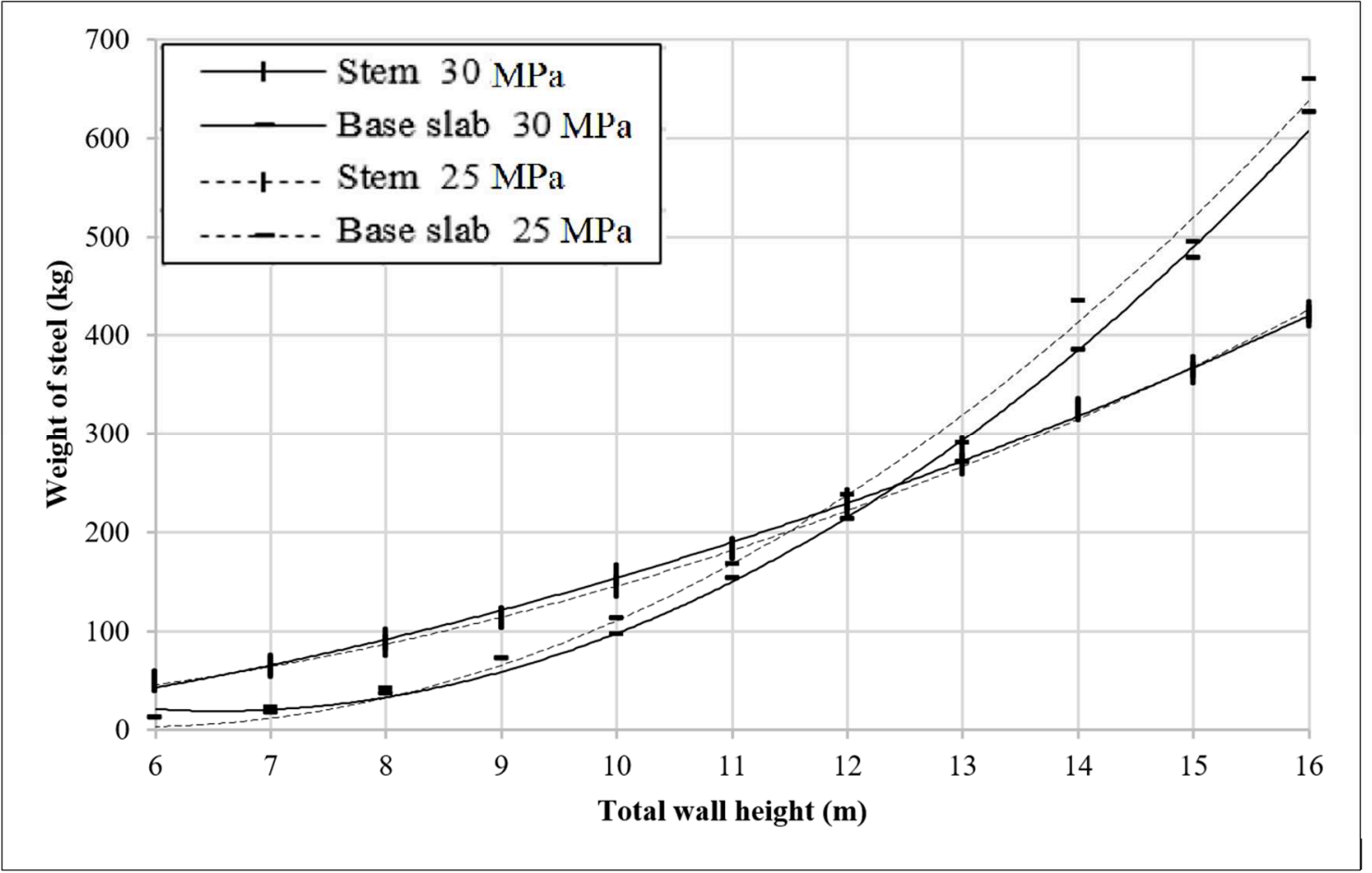

631 Fig. 15. Sensitivity to the concrete strength: weight of steel in stem and base slab

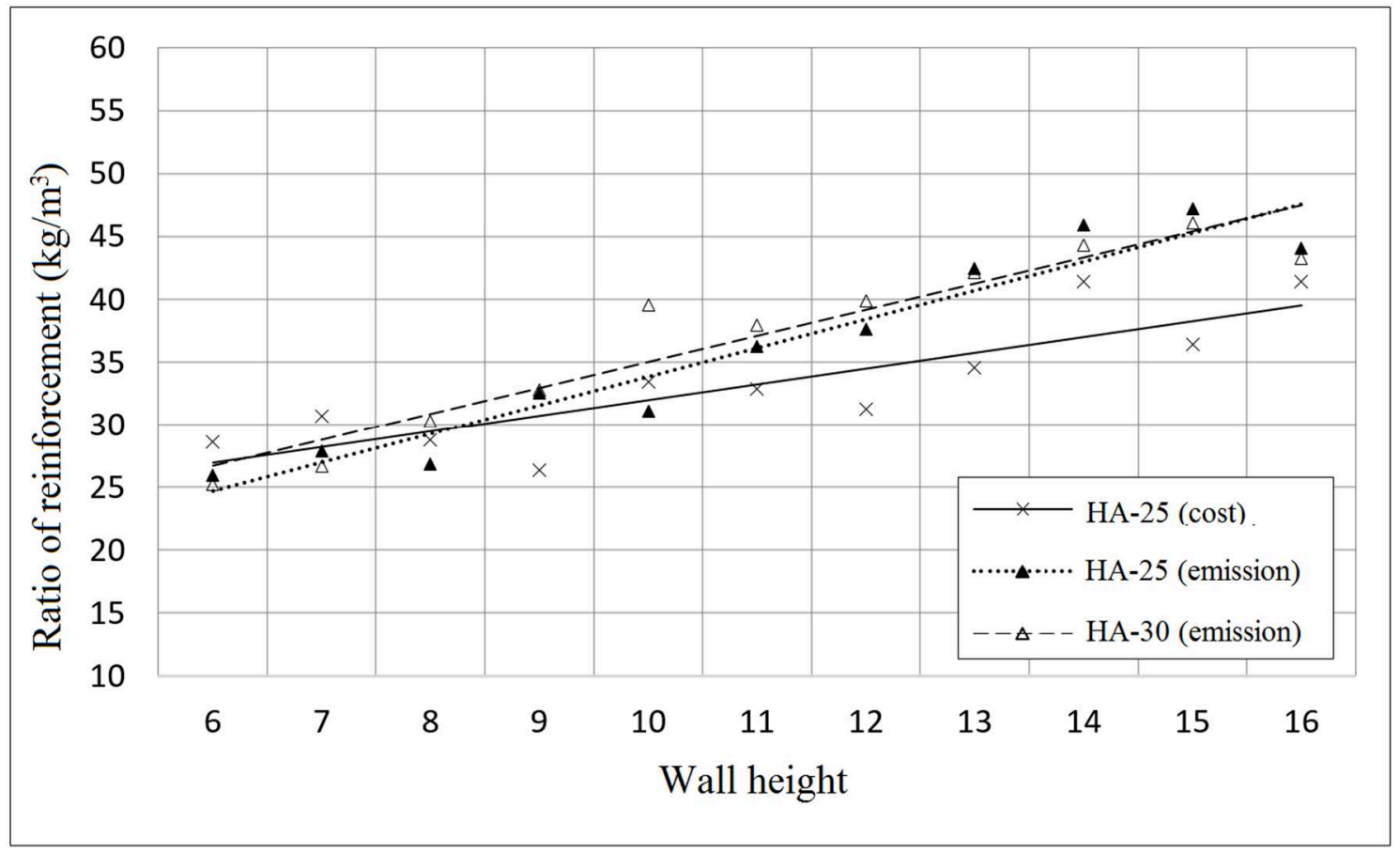

Fig. 16. Ratio of reinforcement by optimization strategy and concrete class (based on the mean optimum values)

635

636 
Table 1. Unit breakdown of emissions and cost

\begin{tabular}{|c|c|c|}
\hline Unit & $\begin{array}{c}\text { Emissions } \\
\text { (CO2-eq) }\end{array}$ & Cost $(€)$ \\
\hline kg of steel B400 & 3.02 & 0.56 \\
\hline $\mathrm{kg}$ of steel B500 & 2.82 & 0.58 \\
\hline$m 3$ of concrete HA-25 in stem & 224.34 & 56.66 \\
\hline m3 of concrete HA-30 in stem & 224.94 & 60.80 \\
\hline m3 of concrete HA-35 in stem & 265.28 & 65.32 \\
\hline m3 of concrete HA-4O in stem & 265.28 & 70.41 \\
\hline m3 of concrete HA-45 in stem & 265.91 & 75.22 \\
\hline$m 3$ of concrete HA-50 in stem & 265.95 & 80.03 \\
\hline m2 stem formwork & 1.92 & 21.61 \\
\hline m3 of backfill & 28.79 & 5.56 \\
\hline m3 of concrete HA-25 in foundation & 224.34 & 50.65 \\
\hline$m 3$ of concrete $H A-30$ in foundation & 224.94 & 54.79 \\
\hline m3 of concrete HA-35 in foundation & 265.28 & 59.31 \\
\hline m3 of concrete $H A-40$ in foundation & 265.28 & 64.40 \\
\hline$m 3$ of concrete $H A-45$ in foundation & 265.91 & 69.21 \\
\hline m3 of concrete HA-50 in foundation & 265.95 & 74.02 \\
\hline
\end{tabular}

640

641

642

643

Table 2. Set of design discrete variables

\begin{tabular}{|c|c|c|c|c|c|}
\hline Variables & & $\begin{array}{l}\mathrm{N}^{\circ} \text { of possible } \\
\text { values in range }\end{array}$ & Increment (step size) & $\begin{array}{l}\text { Lower Bound } \\
\text { (cm) }\end{array}$ & $\begin{array}{l}\text { Upper bound } \\
\text { (cm) }\end{array}$ \\
\hline$c z$ & & $188^{*}$ & $1 \mathrm{~cm}$ & $80^{*}$ & $267 *$ \\
\hline em & & 200 & $1 \mathrm{~cm}$ & 25 & 224 \\
\hline$l p$ & & 800 & $1 \mathrm{~cm}$ & 20 & 819 \\
\hline$l t$ & & 2000 & $1 \mathrm{~cm}$ & 20 & 2019 \\
\hline$e_{c}$ & & 60 & $2.5 \mathrm{~cm}$ & 25 & 172.5 \\
\hline$d c$ & & $481 *$ & $5 \mathrm{~cm}$ & 320 & 800 \\
\hline$f_{\text {ck }}$ & & 6 & $25,20,25,40,45,50$ & & \\
\hline$f_{\mathrm{yk}}$ & & 2 & 400,500 & & \\
\hline \multirow{3}{*}{$A_{1}$ a $A_{10}$} & $\varnothing$ & 8 & $6,8,10,12,16,20,25,32$ & & \\
\hline & $\mathbf{n}$ & 16 & 1 steel rebar & 2 & 17 \\
\hline & $\varnothing$ & 8 & $4,5,6,7,8,9,10$ & & \\
\hline$A_{11}$ a $A_{12}$ & n & 7 & 1 steel rebar & 4 & 10 \\
\hline
\end{tabular}


Table 3. Fixed parameters in the design parametric study

\begin{tabular}{cc}
\cline { 2 - 3 } Parameter considered & Value \\
\cline { 2 - 3 } Bearing capacity & $0.3 \mathrm{MPa}$ \\
Fill slope & 0 \\
Foundation depth, $H_{2}$ & $2 \mathrm{~m}$ \\
Uniform load on top of the fill, $\gamma$ & $10 \mathrm{kN} / \mathrm{m}^{2}$ \\
Wall-fill friction angle, $\delta$ & $0^{\circ}$ \\
Base-friction coefficient, $\mu$ & $\operatorname{tg} 30^{\circ}$ \\
Safety coefficient against sliding, $\gamma_{f s}$ & 1.5 \\
Safety coefficient against overturning, $\gamma_{f o}$ & 1.8 \\
EHE safety coefficient for loading & Normal \\
ULS safety coefficient of concrete & 1.5 \\
ULS safety coefficient of steel & 1.15 \\
EHE ambient exposure & IIa \\
\hline
\end{tabular}

Table 4. Set of calibration parameters tested in HSTA

\begin{tabular}{ccccccccc}
\hline n_HMS & HMS & HMCR & HMP & IWI & TI & PAR & $\begin{array}{c}\text { Percentage } \\
\text { of Variables }\end{array}$ & TA \\
\hline 1 & 50 & 0.7 & 0.9 & 150 & 1000 & 0.2 & 0.3 & $1 \%$ \\
4 & 200 & 0.8 & & 300 & 5000 & 0.4 & & $5 \%$ \\
& & 0.85 & & & & & & \\
\hline
\end{tabular}

656

657

Table 5. Best performing results by average objective and deviation in $16 \mathrm{~m}$ walls

\begin{tabular}{|c|c|c|c|c|c|c|c|c|c|c|c|c|}
\hline Average & $\begin{array}{l}\text { Standard } \\
\text { Deviation }\end{array}$ & $\mathbf{n}_{\text {HMS }}$ & HMS & HMCR & HMP & IWI & TI & PAR & $\mathbf{P}_{\mathrm{var}}$ & TA & $\begin{array}{c}\text { Processing } \\
\text { Time (s) }\end{array}$ & $\begin{array}{c}\text { Processing } \\
\text { Time } \\
\text { (min) }\end{array}$ \\
\hline 9019.03 & 102.21 & 1 & $50 * \mathbf{n}_{\text {HMS }}$ & 0.8 & 0.9 & 150 & 1000 & 0.2 & 0.3 & $5 \%$ & 213.914 & 3.57 \\
\hline 8979.43 & 186.32 & 1 & $50^{*} \mathbf{n}_{\mathrm{HMS}}$ & 0.85 & 0.9 & 150 & 5000 & 0.2 & 0.3 & $1 \%$ & 228.945 & 3.82 \\
\hline 8630.65 & 176.95 & 4 & $200 * \mathbf{n}_{\mathrm{HMS}}$ & 0.85 & 0.9 & 300 & 1000 & 0.2 & 0.3 & $1 \%$ & 2173.315 & 36.22 \\
\hline 8568.83 & 150.02 & 4 & $200 * \mathbf{n}_{\mathrm{HMS}}$ & 0.7 & 0.9 & 300 & 5000 & 0.2 & 0.3 & $1 \%$ & 2932.251 & 48.87 \\
\hline 8025.86 & 116.35 & 4 & $50 * \mathbf{n}_{\text {HMS }}$ & 0.8 & 0.9 & 150 & 5000 & 0.2 & 0.3 & $1 \%$ & 967.855 & 16.13 \\
\hline $\begin{array}{l}\text { Parai } \\
\text { consi }\end{array}$ & $\begin{array}{l}\text { neters } \\
\text { dered: }\end{array}$ & 4 & $\mathbf{5 0} * \mathbf{n}_{\text {HMS }}$ & 0.8 & 0.9 & 150 & 5000 & 0.2 & 0.3 & $1 \%$ & & \\
\hline
\end{tabular}


Table 6. Percentage of total emissions $\left(\mathrm{kgCO}_{2} / \mathrm{m}\right)$ of the wall by components

\begin{tabular}{|c|c|c|c|c|c|c|c|c|c|c|c|c|c|}
\hline $\begin{array}{c}\text { Wall height } \\
\text { Emission source }\end{array}$ & 4 & 5 & 6 & 7 & 8 & 9 & 10 & 11 & 12 & 13 & 14 & 15 & 16 \\
\hline Concrete in stem & 40 & 39 & 37 & 34 & 27 & 23 & 21 & 19 & 17 & 15 & 18 & 17 & 16 \\
\hline Concrete in buttress & 8 & 9 & 10 & 11 & 12 & 14 & 15 & 16 & 14 & 15 & 12 & 12 & 11 \\
\hline Concrete in base slab & 18 & 17 & 16 & 18 & 22 & 23 & 23 & 26 & 26 & 26 & 27 & 27 & 32 \\
\hline Concrete Total & 65 & 65 & 62 & 61 & 61 & 60 & 59 & 59 & 58 & 57 & 57 & 56 & 55 \\
\hline Steel in stem & 13 & 15 & 17 & 17 & 17 & 16 & 17 & 15 & 16 & 16 & 15 & 15 & 14 \\
\hline Steel in base slab & 4 & 4 & 5 & 6 & 7 & 9 & 12 & 13 & 14 & 16 & 18 & 19 & 21 \\
\hline Steel Total & 17 & 18 & 21 & 23 & 24 & 26 & 28 & 28 & 30 & 32 & 33 & 35 & 36 \\
\hline Stem formwork & 3 & 3 & 3 & 3 & 3 & 2 & 2 & 2 & 2 & 2 & 2 & 2 & 1 \\
\hline Base slab formwork & 0 & 0 & 0 & 0 & 0 & 0 & 0 & 0 & 0 & 0 & 0 & 0 & 0 \\
\hline Earth removal (heel) & 3 & 3 & 2 & 2 & 2 & 2 & 2 & 1 & 1 & 1 & 1 & 1 & 1 \\
\hline Earth removal (toe) & 0 & 0 & 0 & 0 & 0 & 0 & 0 & 0 & 0 & 0 & 0 & 0 & 0 \\
\hline Backfill & 11 & 11 & 10 & 10 & 10 & 10 & 9 & 9 & 9 & 8 & 7 & 7 & 6 \\
\hline
\end{tabular}

669

670

671

672

Table 7. Ratio emission/cost of the steel per optimization strategy

\begin{tabular}{cccc}
\hline Height $(\mathbf{m})$ & Steel Total & Steel in stem & Steel in base slab \\
\hline 4 & 1.06 & 1.15 & 0.81 \\
5 & 0.99 & 1.12 & 0.68 \\
6 & 0.95 & 1.05 & 0.75 \\
7 & 0.92 & 0.95 & 0.84 \\
8 & 1.02 & 0.99 & 0.98 \\
9 & 1.02 & 0.97 & 1.08 \\
10 & 0.97 & 0.94 & 1.03 \\
11 & 1.02 & 0.97 & 1.08 \\
12 & 0.98 & 0.94 & 1.02 \\
13 & 1.04 & 1.03 & 1.06 \\
14 & 1.04 & 1.08 & 1.04 \\
15 & 1.06 & 1.03 & 1.06 \\
16 & 1.09 & 1.05 & 1.07 \\
\hline
\end{tabular}

673 